NBER WORKING PAPER SERIES

\title{
UNEMPLOYMENT AND DEVELOPMENT
}

\author{
Ying Feng \\ David Lagakos \\ James E. Rauch \\ Working Paper 25171 \\ http://www.nber.org/papers/w25171 \\ NATIONAL BUREAU OF ECONOMIC RESEARCH \\ 1050 Massachusetts Avenue \\ Cambridge, MA 02138 \\ October 2018
}

For helpful comments we thank Gary Fields, Chris Huckfeldt, Ben Moll, Andi Mueller, Tommaso Porzio, Guillaume Rocheteau, Venky Venkateswaran, Mike Waugh, Erin Wolcott, Randy Wright and seminar/conference audiences at Cornell, Harvard/MIT, NYU, Rochester, Midwest Macro (Pittsburgh), SED (Mexico City), China Conference on Development and Growth (Wuhan), the MacCaLM Workshop (Edinburgh), Trinity College Dublin, UCSD and the West Coast Search Conference (Irvine). All potential errors are our own. The views expressed herein are those of the authors and do not necessarily reflect the views of the National Bureau of Economic Research.

NBER working papers are circulated for discussion and comment purposes. They have not been peer-reviewed or been subject to the review by the NBER Board of Directors that accompanies official NBER publications.

(C) 2018 by Ying Feng, David Lagakos, and James E. Rauch. All rights reserved. Short sections of text, not to exceed two paragraphs, may be quoted without explicit permission provided that full credit, including $\odot$ notice, is given to the source. 
Unemployment and Development

Ying Feng, David Lagakos, and James E. Rauch

NBER Working Paper No. 25171

October 2018

JEL No. E24,E26,O11,O41

\begin{abstract}
$\underline{\text { ABSTRACT }}$
This paper draws on household survey data from countries of all income levels to measure how average unemployment rates vary with income per capita. We document that unemployment is increasing with GDP per capita. Furthermore, we show that this fact is accounted for almost entirely by low-educated workers, whose unemployment rates are strongly increasing in GDP per capita, rather than by high-educated workers, whose unemployment rates are not correlated with income. To interpret these facts, we build a model with workers of heterogeneous ability and two sectors: a traditional sector, in which self-employed workers produce output without reward for ability; and a modern sector, in which firms hire in frictional labor markets, and output increases with ability. Countries differ exogenously in the productivity level of the modern sector. The model predicts that as productivity rises, the traditional sector shrinks, as progressively less-able workers enter the modern sector, leading to a rise in overall unemployment and in the ratio of low-educated to high-educated unemployment rates. Quantitatively, the model accounts for around one third of the cross-country patterns we document.

Ying Feng

Department of Economics

University of California, San Diego

La Jolla, CA 92093-0508

yif014@ucsd.edu

David Lagakos

Department of Economics, 0508

University of California, San Diego

9500 Gilman Drive

La Jolla, CA 92093

and NBER

lagakos@ucsd.edu

James E. Rauch

Department of Economics

University of California, San Diego

La Jolla, CA 92093-0508

and NBER

jrauch@ucsd.edu
\end{abstract}




\section{Introduction}

No single measure of labor-market performance receives more attention among academics and policy makers than the unemployment rate. It is well known, for example, that average unemployment rates are higher in Western Europe than in the United States and Japan. But there is little systematic evidence about how average unemployment rates vary across the entire world income distribution. Internationally comparable data from the poorest countries of the world are particularly lacking. This lack of data hampers research on the determinants of national average unemployment levels, and on the link between unemployment and development, to name two important topics.

This paper attempts to fill this gap by building a database of national unemployment rates covering countries of all income levels. To do so, we draw on evidence from 199 household surveys from 84 countries spanning 1960 to 2015. The database covers numerous rich countries and around two dozen nations from the bottom quartile of the world income distribution. Since measures of employment and job search vary across surveys, we divide the data into several tiers based on scope for international comparability. We then construct unemployment rates at the aggregate level and for several broad demographic groups, and compare how they vary with average income.

We find, perhaps surprisingly, that unemployment rates are increasing in GDP per capita. This finding is present for men and for women, for all broad age groups, within urban and rural areas, and across all comparability tiers of our data. For prime-aged adults, a regression of the country average unemployment rate on log GDP per capita yields a statistically significant positive coefficient of 1.8 percent. Our findings contrast with the (scarce) existing evidence in the literature, and in particular, the work of Caselli (2005), who finds in an earlier database that unemployment rates do not systematically vary with income per capita.

In addition, we document that unemployment patterns across countries differ markedly by education level. Among high-educated workers (secondary school or more), unemployment rates do not vary systemically with GDP per capita. Among low-educated workers, in contrast, unemployment rates are substantially higher in rich countries. Regressing the country average high-educated unemployment on log GDP per capita yields an insignificant slope coefficient of 0.5 percent, whereas the slope coefficient for the low-educated is a significant 3.2 percent. Our data imply that in rich countries, low-educated workers are more likely than high-educated workers to be unemployed. In poor countries, the opposite is true, and unemployment is concentrated among the high-educated.

To understand these facts, we build a simple two-sector model with frictional labor markets, based on Diamond (1982) and Mortensen and Pissarides (1994), and heterogeneous workers 
that sort by ability as in Roy (1951). In the modern sector, labor markets are governed by search frictions, and worker productivity is determined by a worker's ability level. In the traditional sector, workers are self-employed and do not need to search for jobs; however, productivity is independent of ability. Outputs of the modern and traditional sectors are perfect substitutes, and firms operate competitively in the modern sector, with unrestricted entry. Countries differ exogenously in modern-sector productivity, with a single traditionalsector technology available to all countries. This assumption builds on the mounting evidence that cross-country productivity differences are skill-biased, as opposed to skill neutral (see, e.g., Caselli and Coleman, 2006; Hjort and Poulsen, forthcoming; Jerzmanowski and Tamura, 2017; Malmberg, 2016).

Our simple model has several main theoretical predictions that are qualitatively consistent with the facts we document. First, as modern-sector productivity increases, the traditional sector shrinks, as progressively less able workers sort into the modern sector. Second, as modern-sector productivity increases, the aggregate unemployment rate increases. This is because as the modern sector expands, a greater fraction of workers now search for jobs in frictional labor markets rather than working in self-employment. Moreover, the job-finding rate falls in equilibrium, since average ability is lower in the modern sector. Third, as productivity increases, unemployment rates rise faster for less able than for more able workers, since a greater share of less able workers are drawn into job search. This third prediction is consistent with the rising ratio of unemployment for low- to high-educated workers with GDP per capita that we document.

To assess the model's quantitative predictions, we extend the simple model in several ways so as to be consistent with salient features of the cross-country data. In particular, we allow modern and traditional sector outputs to be imperfect substitutes, and we allow countries to differ exogenously in both traditional- and modern-sector productivity. We also allow for two education groups, with the distribution of ability for the high-educated group stochastically dominating that of the low-educated. We calibrate the distribution of ability using moments of the U.S. wage distribution, and parameterize other aspects of the model to match key moments of the U.S. labor market - in particular the average unemployment rate and the ratio of the unemployment rate for low- to high-educated workers.

Our main quantitative experiment lowers productivity in the modern and traditional sectors, as well as the fraction of high-educated workers, and then computes how the model's predictions for unemployment - in the aggregate and by education level -vary with GDP per capita. We discipline the cross-country values of modern-sector productivity to match GDP per capita levels across the world income distribution, and we discipline traditional-sector productivity to match the relative prices of traditional goods. We proxy traditional sector employment in the data by the set of workers who are self-employed without paid employees, and who work 
in low-skilled occupations. Not surprisingly, this share is strongly decreasing in GDP per capita, ranging from around three quarters of the workforce in poor countries to less than three percent in the richest countries. ${ }^{1}$

The calibrated model predicts that unemployment rates are increasing in GDP per capita, as in the data, though the model underpredicts the magnitude of the relationship. Compared to the observed 1.8 percentage-point increase in unemployment for an increase in one log point of GDP per capita, the model predicts an increase of 0.5 percent. For unemployment by education, the model correctly predicts that the ratio of low- to high-educated unemployment is increasing in GDP per capita. Yet it again underpredicts the magnitude of the relationship, with a semi-elasticity of 0.47 in the data compared to 0.25 in the model. We conclude that our mechanism explains 30 percent of the relation between aggregate unemployment and average income, and 53 percent of the relation between the unemployment ratio and average income. Furthermore, the model's predicted share of employment in the traditional sector by GDP per capita corresponds closely with the data. We also show that our results are sensitive to one parameter value in particular: the elasticity of substitution between modern and traditional sector outputs, which governs the strength of our mechanism, the decline of the traditional sector.

As an alternative and complementary theory, we incorporate the less generous unemployment benefits of poor countries relative to richer countries. In the model, lower unemployment benefits in poorer countries discourage search, thus lowering unemployment rates in equilibrium. We find that adding this alternative mechanism increases the explanatory power of our quantitative model from 30 percent to 41 percent of the slope of the aggregate unemployment rate in GDP per capita. On the other hand, it offers little additional explanatory power for the relation between the ratio of low- to high-educated unemployment and income. We conclude that our quantitative model explains a substantial fraction of the cross-country unemployment patterns that we document, but that even including the less generous social security nets of poorer countries, there is a lot left unexplained by the model.

We close the paper by presenting historical data on unemployment from the United States and four other advanced countries for which long time series on unemployment are available: Australia, France, Germany and the United Kingdom. We ask whether unemployment rates are higher now than they were before World War I, which is the earliest period for which unemployment data are available, to our knowledge. We find that for all countries, average unemployment rates are indeed higher now than they were before World War I, and for

\footnotetext{
${ }^{1}$ Note that this decrease in the traditional sector after excluding agriculture is of similar magnitude, ranging from around half of the workforce to less than two percent. Thus, the traditional sector is not simply agriculture, but represents the unskilled self-employment that is widespread throughout developing economies (see e.g. Feng and Rickey, 2016; Gollin, 2008; Schoar, 2010).
} 
four of the five countries, the difference is statistically significant. Using the U.S. data, which we have at a more disaggregated level, we ask in addition whether unemployment is particularly higher now for the less-educated. We find that average unemployment has indeed risen faster for the less-educated than for the more-educated, at least since 1940. In 1940, the less-educated were about 1.5 times as likely to be unemployed as the more-educated. Today, the ratio is close to 2.5. We conclude that historical unemployment data are broadly consistent with our cross-country findings, suggesting that unemployment is largely a feature of advanced economies, rather than a by-product of under-development.

Related Literature. Most of the literature on average unemployment differences across countries has focused on Europe and the United States (see, e.g., Blanchard and Summers, 1986; Ljungqvist and Sargent, 2008; Nickell, Nunziata, and Ochel, 2004). The few studies that have addressed unemployment across a wider range of income levels have come to contradictory conclusions, most likely due to a lack of comparable cross-country data. Banerjee, Basu, and Keller (2016) compile World Bank unemployment data that suggest a decreasing pattern of unemployment in income per capita, though their data are largely from middle-income and richer countries. Perhaps the most systematic look at aggregate unemployment rates across countries is by Caselli (2005), who draws on a 1996 World Bank dataset covering 60 countries. These data show no correlation between GDP per capita and average unemployment, though they cover just three countries in the bottom half of the world income distribution. Older studies did not have sufficient data points to draw firm conclusions about cross-country patterns, but tended to find that unemployment rates in developing economies studies were not that different from those of richer economies (see, e.g., Fields, 1980, 2004; Squire, 1981; Turnham, 1993). More recently, Poschke (2018) draws on surveys from 68 countries to study the relationship between self-employment and the ratio of unemployment to wage employment. His explanation emphasizes differences in labor market frictions across countries, whereas our theory emphasizes different forces altogether.

Our paper is closely related to the growing literature on structural change, though our two sectors do not fit neatly into the standard agriculture-manufacturing-services division (used by e.g. Duarte and Restuccia, 2010; Herrendorf, Rogerson, and Valentinyi, 2014; Mestieri, Comin, and Lashkari, 2018). ${ }^{2}$ In our modern and traditional sectors, we emphasize skilled wage employment versus unskilled self-employment, both of which can be present within the agriculture, manufacturing, and service sectors. In this way, our sectors are closer to the split between high-educated services and low-educated services taken by Buera and Kaboski (2012)

\footnotetext{
${ }^{2}$ Other multi-sector models in macro split the economy into the consumption vs investment sectors (Hsieh and Klenow, 2007; Restuccia and Urrutia, 2001), goods vs service sectors (e.g. Boppart, 2014), urban vs rural areas (Cavalcanti, Monge-Naranjo, and Torres de Mello, 2016; Young, 2013), or agriculture vs non-agriculture sectors (e.g. Adamopoulos and Restuccia, 2014; Lagakos and Waugh, 2013; Porzio and Santangelo, 2017). Our modern-traditional division does not correspond cleanly to these splits either.
} 
and Buera, Kaboski, and Rogerson (2015), though their models focus on non-homothetic preferences, which play no role in our theory.

By emphasizing the transition from self-employment to wage employment in frictional labor markets, our paper builds on the macroeconomic literature on home production and its role in the development process. This transition to market production with development is a key theme in the model of Ngai and Pissarides (2008), for example. Gollin, Parente, and Rogerson (2004) argue that measured output differences across countries may be overstated due to missing home production in poorer countries. Similarly, Parente, Rogerson, and Wright (2000) show that policies that distort capital accumulation can lead to bigger output losses once a home production sector is introduced into a standard neoclassical growth model, since capital distortions encourage producers to move into self-employment. Empirically, Bridgman, Duernecker, and Herrendorf (2018) show that the share of household production in total hours decreases with GDP per capita. None of these studies focuses on the link between unemployment and development, however.

Finally, our paper builds on the old literature on two-sector models in development, particularly Lewis (1954) and Harris and Todaro (1970). However, our model is focused on the determinants of actual measured unemployment (often called "open unemployment"), as opposed to "underemployment" or "disguised unemployment," which corresponds to some extent to our traditional sector. Negative selection into our traditional sector is also quite related to the negative selection into the "informal sector" as characterized by Rauch (1991), La Porta and Shleifer (2008, 2014) and others. Unlike Harris and Todaro (1970), the urban-rural divide plays no role in our theory; we find similar unemployment patterns in both rural and urban areas and, hence, abstract from them.

\section{Data}

This section describes the household survey data that we use to measure unemployment in the aggregate and by demographic group across our set of countries.

\subsection{Data Sources}

Our data come from household surveys or censuses that are nationally representative. Many, but not all, are available from the International Integrated Public Use Microdata Surveys (IPUMS) (Minnesota Population Center, 2017) or the World Bank's Living Standards Measurement Surveys (LSMS). Tables A.1, A.2 and A.3 in the Appendix list the full set of surveys employed, plus their sources. The key benefit of nationally representative surveys, as 
opposed to (say) administrative records on unemployment, is that they cover all individuals, including the self-employed. In total, our analysis includes 199 country-year surveys, covering 84 countries, and spanning 1960 to 2015. Most of our data come from the 1990s and 2000s. ${ }^{3}$

To measure GDP per capita, we divide output-side real GDP at chained PPPs (in 2011 US\$) by population, both taken from the Penn World Tables 9.0. Unlike in previous studies, our data have a high representation of the world's poorest countries, with 23 countries from the bottom quartile of the world income distribution, and 27 from the second quartile.

In our main analysis, we restrict attention to prime-aged adults (aged 25-54) of both sexes. We also report our results for males and females separately, for broader age groups, and for urban and rural regions. Throughout, we exclude those with missing values of key variables and those living in group quarters. We use sample weights whenever they are available.

\subsection{Unemployment Definition and Data Tiers}

We define an unemployed person as one who (1) is not employed, and (2) has searched recently for a job. We define employment following the U.N. System of National Accounts as "all persons, both employees and self-employed persons, engaged in some productive activity that falls within the production boundary of the SNA" (United Nations, 2008). Thus, we count those working in self-employment as employed. We define the unemployment rate as the ratio of unemployed workers to employed plus unemployed workers. ${ }^{4}$

The key measurement challenge we face is that not all surveys allow us to define unemployment in exactly the same way. To ensure that our cross-country comparisons are as informative as possible, we divide the surveys into tiers, based on their international comparability. Tier 1 has the highest scope for comparability, followed by Tier 2 and then Tier 3. We describe these further below.

In Tier 1 and Tier 2 countries, employment specifically covers all economic activities that produce output counted in the National Income and Product Accounts (NIPA). In other words, employment specifically comprises wage employment, self-employment or work at a family business or farm, whether or not the output is sold or consumed directly. ${ }^{5}$ With regard

\footnotetext{
${ }^{3}$ Donovan, Lu, and Schoellman (2018) use surveys from 13 countries to document high-frequency labor market patterns in the urban areas of middle and high income countries. Our paper covers many more low income countries, whereas their study brings in repeated observations from the same individuals.

${ }^{4}$ The BLS Handbook of Methods defines an unemployed individual as one who (1) is not employed, (2) has searched recently for a job, and (3) is "available to work" (U.S. Bureau of Labor Statistics, 2016). However, only 49 of our 199 country-year surveys asked whether the interviewee is "available for work" in some way.

${ }^{5}$ See e.g. Gollin, Lagakos, and Waugh (2014) for a more detailed treatment of which outputs are covered in NIPA. Not counted is work on home-produced services such as cooking, cleaning or care of one's own children. Home-produced services are not counted in NIPA, and previous studies of time use, such as Aguiar and Hurst (2007b), Ramey and Francis (2009) and Bick, Fuchs-Schuendeln, and Lagakos (2018), treat these
} 
to recent job search, Tier 1 includes surveys in which workers who searched did so either in the last week or the last four weeks. Tier 2 includes surveys in which workers are searching "currently" (without specifying a time frame) or in some time period other than the last week or last four weeks, such as the last two months.

In Tier 3 countries, the employment question has lower scope for comparability. It may, for example, consider those working for their own consumption or those not working for a monetary wage as non-employed. It may include a minimum number of hours worked, or cover only a specific period of time, such as the last seven days. Appendix Table A.3 lists the way in which each country in Tier 3 has a non-standard employment question. In terms of job search, Tier 3 countries cover any time.

All in all, our dataset consists of 129 Tier 1 surveys, 40 Tier 2 surveys and 30 Tier 3 surveys. In our empirical findings below, we begin with data from all tiers, which maximizes the number of observations available. We then restrict attention to Tier 1 first, followed by Tiers 1 and 2, to explore how our results change when we take into consideration a smaller but more comparable set of countries.

\subsection{Comparison to ILO and World Bank Data}

Two readily downloadable sources of data on unemployment rates at the country level are the "ILO modeled estimates" from the International Labor Office (ILO), and the World Bank's World Development Indicators (which are in fact derived directly from the ILO). However, many of the ILO's modeled estimates are, by definition, modeled or imputed rather than computed directly from an underlying survey. Even by the ILO's own admission, the modeled estimates are fraught with serious non-comparabilities. For example, some estimates cover only main cities or metropolitan areas, while others use non-standard employment definitions that exclude self-employed workers or first-time job seekers.

Acknowledging the lack of international comparability in its full database, the ILO also publishes "ILO-comparable" unemployment rates from 30 countries, which are always based on a household labor force survey (Lepper, 2004). Unfortunately, the ILO-comparable unemployment rates have very limited coverage of the bottom half of the world income distribution, covering just one such country. Therefore, the ILO-comparable unemployment dataset is ill-suited to answer the question of how average unemployment rates vary between poor and rich countries. In addition, it does not provide disaggregated unemployment rates, such as by education level, which we show are crucial to understanding the aggregate patterns. If one nonetheless uses these ILO data to estimate how average unemployment rates vary

categories as "home production" rather than as work. 
with income per capita, one will find a statistically insignificant or negative relationship. Using the ILO modeled unemployment estimates, a regression of the 2014 unemployment rate on log GDP per capita yields a slope coefficient of 0.02 with a p-value of 0.96 . This lack of correlation between unemployment and income is comparable to what Caselli (2005) found. With the much smaller ILO comparable database, available from 1994 to 2003, the regression coefficient is -3.44 with a p-value of 0.01 . Thus, either of the readily available ILO unemployment databases paint a misleading picture of how unemployment rates vary with income level.

\section{$3 \quad$ Empirical Findings}

In this section, we report how average unemployment rates vary with GDP per capita. We first compare aggregate unemployment rates, and then look beneath the surface at unemployment by sex, by age group and by rural-urban status.

\subsection{Aggregate Unemployment Rate}

Figure 1 plots the country average unemployment rate for prime-aged adults (on a log base 2 scale) against log GDP per capita. The figure includes countries from all three tiers with at least two years of data. The dotted black line - the linear regression line - shows a substantial positive slope. The slope coefficient for a regression of the unemployment rate in natural units on log GDP per capita is 1.8 and is statistically significant at the one-percent level. Taking simple averages by country income quartile, the bottom (poorest) quartile has an average unemployment rate of 2.5 percent. By contrast, the top (richest) quartile has an average unemployment rate of 8.7 percent.

Besides the positive slope, Figure 1 highlights the large variation in average unemployment rates within each income group. To what extent does this variation simply reflect measurement error? To what extent does the correlation of unemployment rates and GDP per capita survive once we restrict attention to more comparable data?

To help answer these questions, we report the slope coefficient of average unemployment on log GDP per capita using various alternative cuts of the data. The first data column of Table 1 reports these slopes. When considering all 199 country-year surveys separately, the slope falls somewhat to 1.1, and is again statistically significant at the one-percent level. When using only Tier 1 surveys, the slope coefficient becomes 1.4, and with Tier 1 and 2 surveys, the slope becomes 1.3. We conclude that the pattern of increasing unemployment is not an artifact of our choice of countries in the main analysis. 
Figure 1: Unemployment Rates by GDP per capita

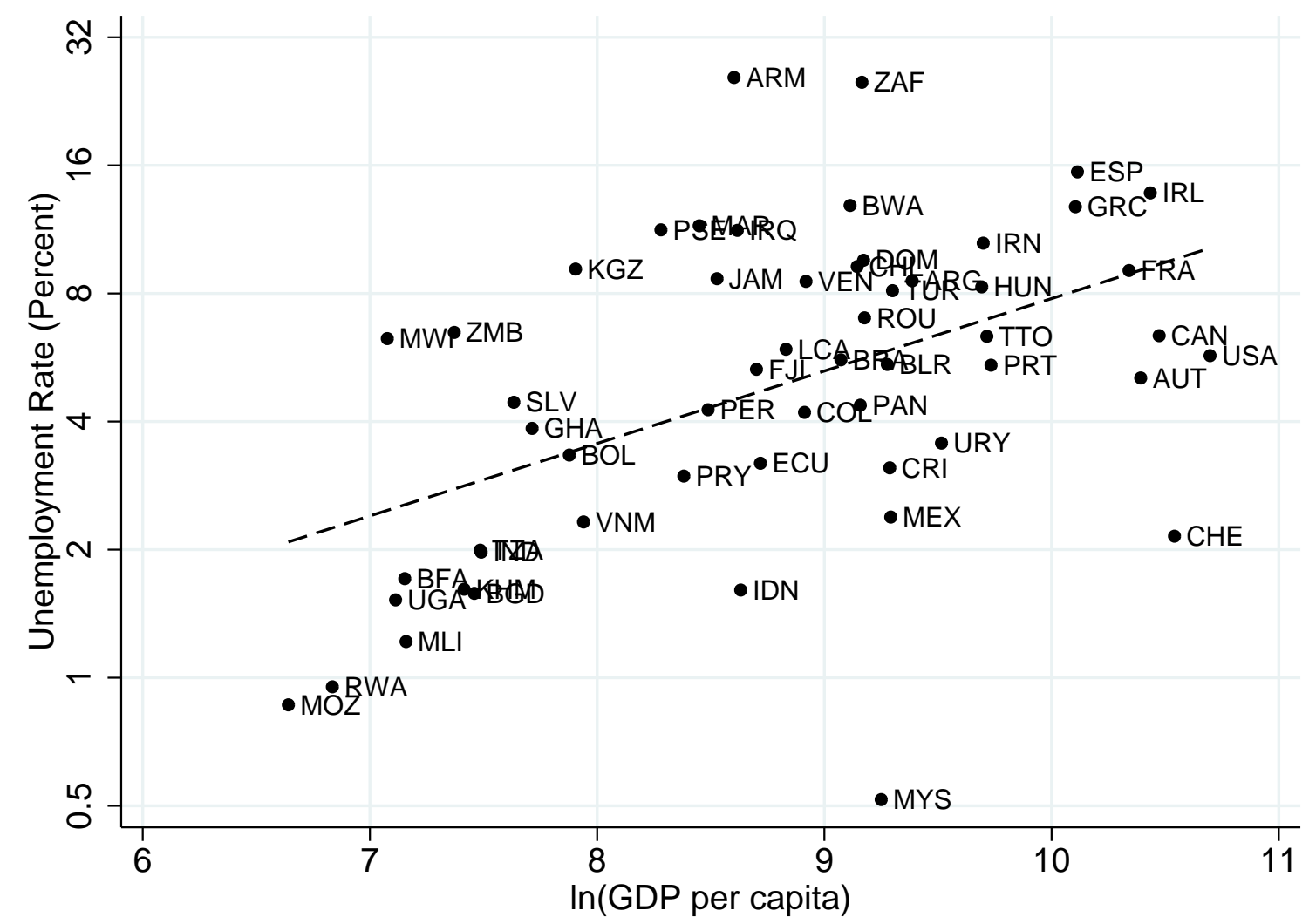

Note: This figure plots the average unemployment rate for prime-aged adults in each country with at least two observations across all years of data from all tiers.

\subsection{Unemployment Rate by Education Level}

In this subsection, we report our findings by education level, which are helpful in accounting for the aggregate patterns we document above. Later we present results by other demographic groups. We define two education groups, which can be measured consistently across nearly all of our countries. The low education group are those that did not finish secondary school. This could mean no school, some or all of primary school completed, some secondary education, or some other specialty education that lasts less than 12 years. The high education group are those that completed secondary school or more. This could mean exactly secondary school, some college or university completed, or an advanced degree.

Figure 2 plots the unemployment rates for prime-aged adults by education group. As before, we plot the unemployment rates in log base 2 and GDP per capita in natural logs. As one can see, the patterns differ sharply by group. For the low-educated group, unemployment is strongly increasing in GDP per capita. For the high-educated group, unemployment rates are 
Figure 2: Unemployment Rates by GDP per capita and Education

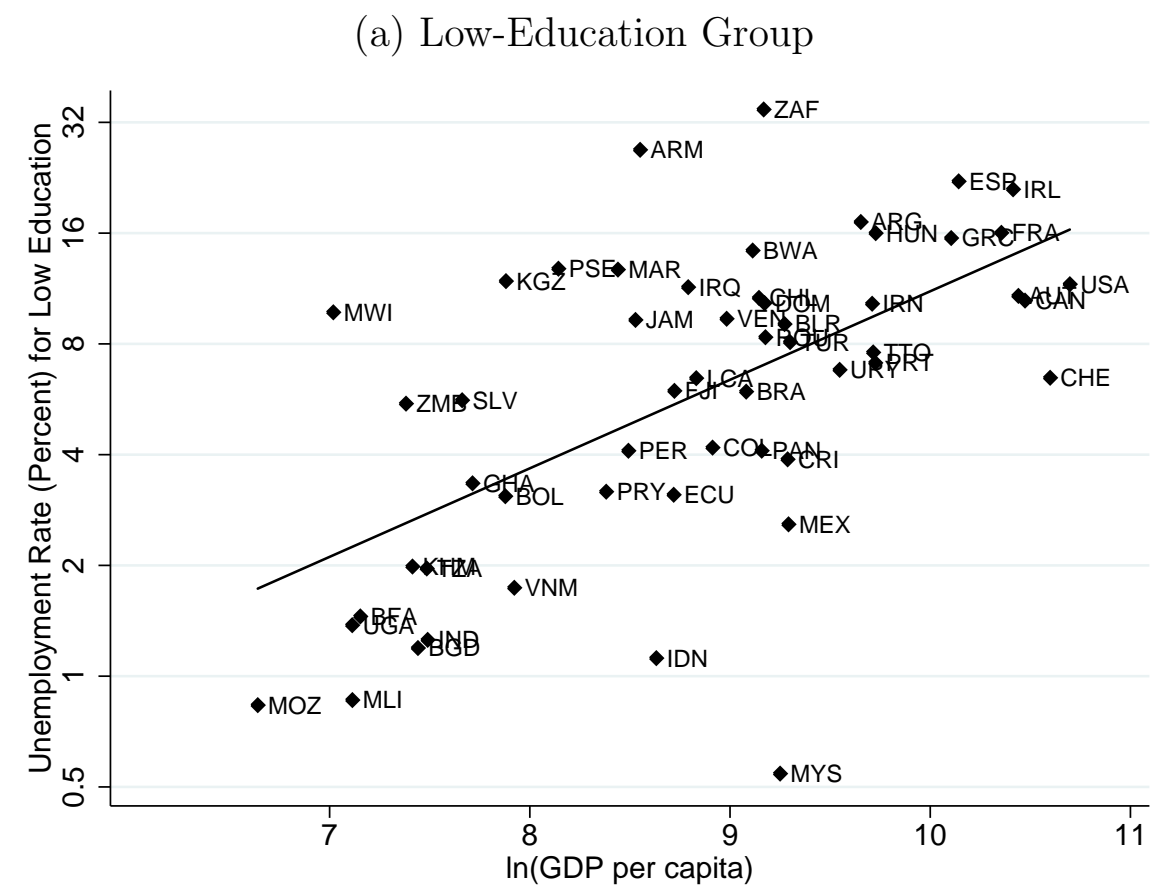

(b) High-Education Group

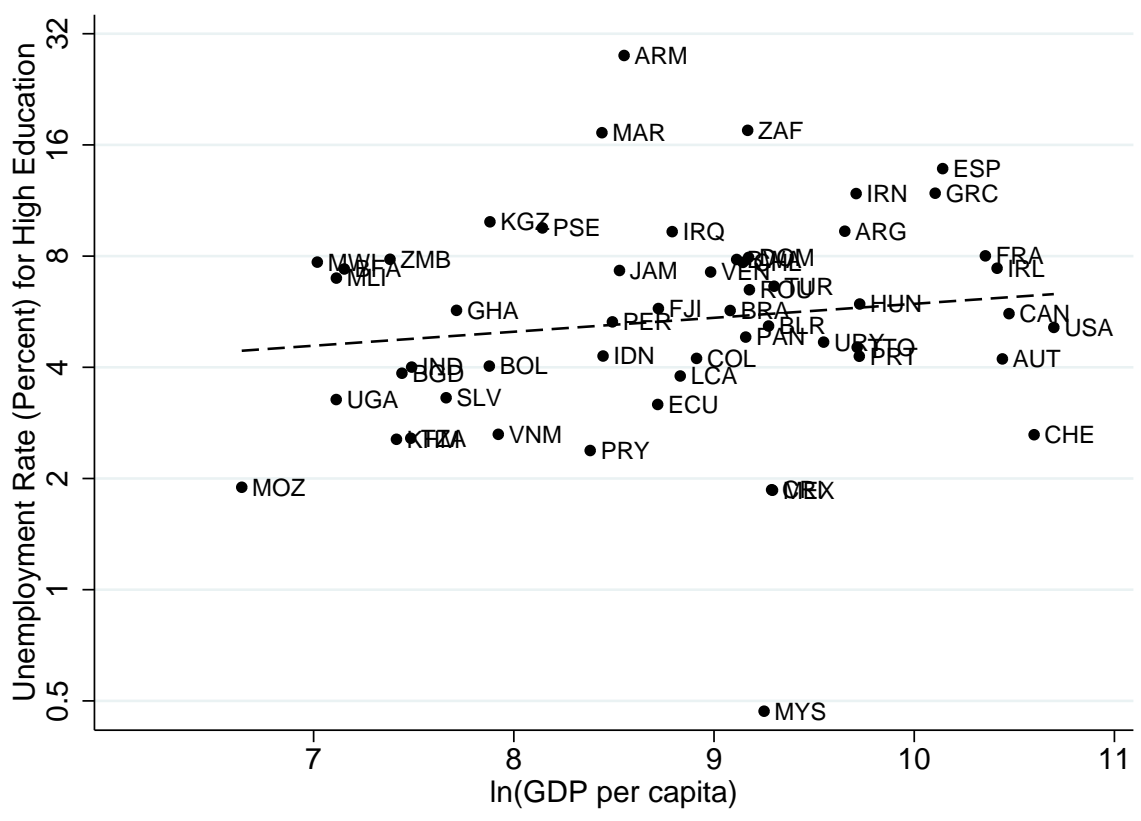

Note: This figure plots the average unemployment rate for prime-aged adults by education level in each country with at least two observations across all years of data from all tiers. Low education means less than secondary school completed; high-education means secondary school completed or more. 
Table 1: Slope Coefficients of Unemployment Rate on GDP per capita

\begin{tabular}{|c|c|c|c|c|c|}
\hline & All Workers & $\mathrm{N}$ & Low Education & High Education & Ratio \\
\hline All surveys & $\underset{(.3)}{1.1^{* * *}}$ & 199 & $\begin{array}{l}2.9^{* * *} \\
(.4)\end{array}$ &.- .2 & $\begin{array}{c}.50^{* * *} \\
(.03)\end{array}$ \\
\hline Country average & $\begin{array}{l}1.8^{* * *} \\
(.5)\end{array}$ & 55 & $\begin{array}{l}3.2^{* * *} \\
(.6)\end{array}$ & $\begin{array}{l}.5 \\
(.4)\end{array}$ & $\begin{array}{c}.48^{* * *} \\
(.05)\end{array}$ \\
\hline Only Tier 1 surveys & $\underset{(.3)}{1.4^{* * *}}$ & 127 & $\begin{array}{l}3.2^{* * *} \\
(.4)\end{array}$ & $\begin{array}{l}.4 \\
(.3)\end{array}$ & $\begin{array}{c}.48^{* * *} \\
(.03)\end{array}$ \\
\hline Only Tier $1+2$ surveys & $\begin{array}{l}1.3^{* * *} \\
(.3)\end{array}$ & 167 & $\underset{(.4)}{2.9^{* * *}}$ & -.1 & $\begin{array}{c}.50^{* * *} \\
(.03)\end{array}$ \\
\hline
\end{tabular}

Note: The table reports the slope coefficient from a regression of the prime-age unemployment rate on $\log$ GDP per capita and a constant. ${ }^{* * *},{ }^{* *}$ and ${ }^{*}$ indicate statistical significance at the 1-percent, 5-percent and 10-percent levels. The first row includes all surveys in our data. The second row includes one observation per country: the average unemployment rate for those with at least two observations across all years from all tiers. The third row includes only Tier 1 surveys. The fourth row includes only Tier 1 and Tier 2 surveys. Surveys with missing education level data are dropped in the last three columns.

roughly constant across income levels. Again, there is quite a lot of variation in unemployment rates for each income level, though somewhat less than for the aggregate unemployment rates. Taking simple averages by income quartile, for the low-educated workers in the bottom quartile, the average unemployment rate is 2.7 percent. This rises to 8.1 percent in the second quartile, 9.5 in the third and 14.3 in the richest quartile. For the high-educated, the average unemployment rate is not monotonically increasing in income per capita. It rises from 4.9 percent in the bottom quartile to 7.7 in the second, and then falls to 6.2 and 7.3 in the third and fourth quartiles.

The third and fourth data columns of Table 1 report the regression coefficients for the low-educated and the high-educated separately. For the low-educated, the coefficient is 2.9 across all surveys, and statistically significant at the one-percent level. When restricted to country averages (i.e., the average across all surveys available for each country), we get a significant slope of 3.2. Across our Tier 1 surveys only, the slope is also 3.2, and when including both Tier 1 and Tier 2 surveys, the slope is 2.9, with statistical significance at the one-percent level in both cases. For the high-educated, in contrast, the slope is statistically insignificantly different from zero in all cases. Across all surveys, the slope coefficient is -0.2 but with a standard error of 0.34 . The estimated slopes are noisy and statistically insignificant for country averages, for Tier 1 and for both Tiers 1 and 2, as well.

Figure 3 plots the ratio of unemployment for the low-educated to that for the high-educated 
Figure 3: Ratio of Unemployment Rates for Low- to High-Educated

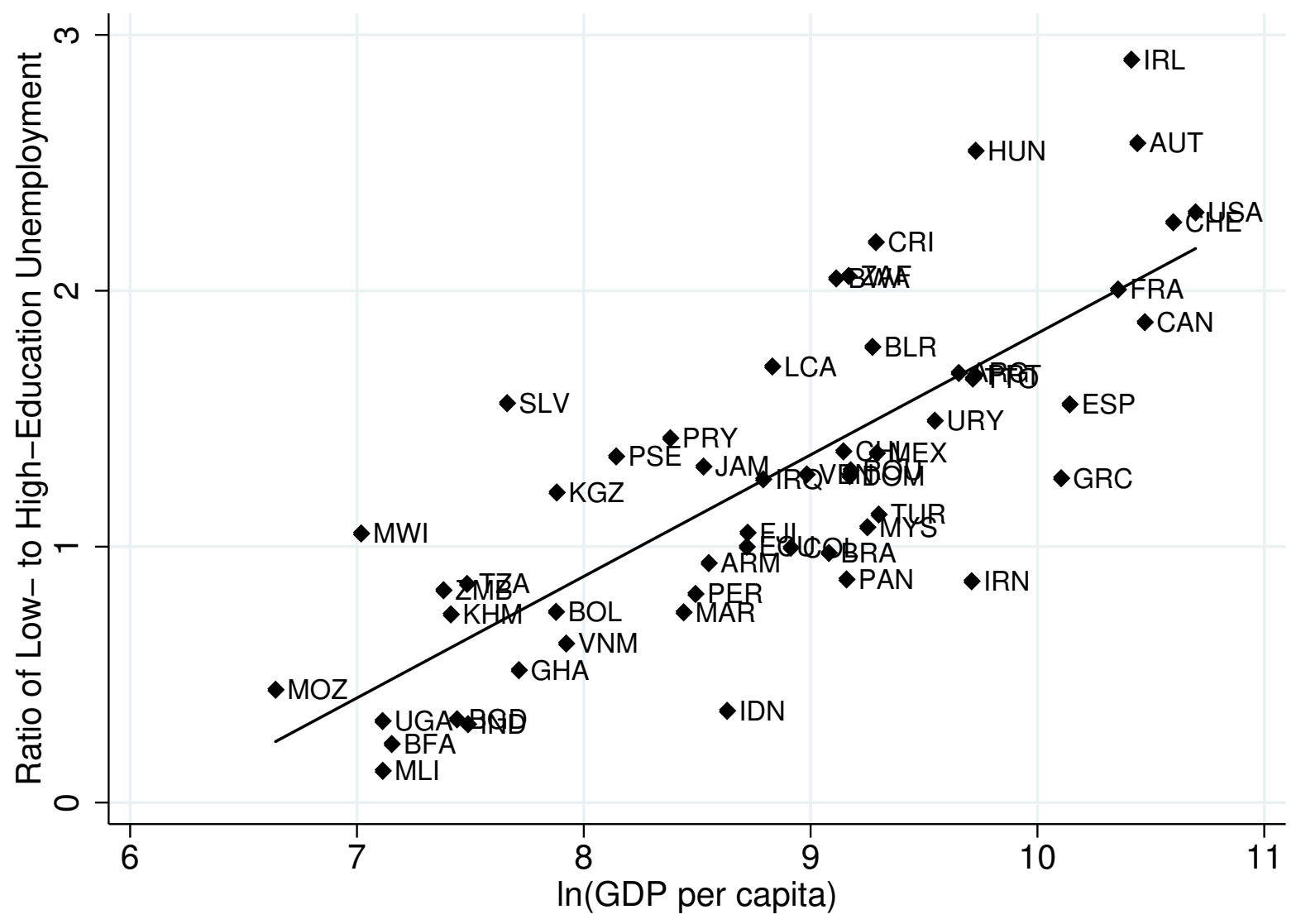

Note: This figure plots the average unemployment ratio of the low-educated workers over the high-educated workers for prime-aged adults across all years of data for each country with at least two years' observations, for Tiers 1, 2 and 3 of surveys. See the Data Appendix for more details.

group. As the figure shows, this ratio is strongly increasing in GDP per capita. It is also less variable across countries within each broad income level than in Figure 1, for example. Virtually all of the poorest countries have ratios less than one, meaning that the low-educated workers are less likely to be unemployed than the high-educated. All of the richest countries have a ratio above one, meaning that the less-educated are more likely than the high-educated to be unemployed. For the poorest quartile of the world income distribution, the average ratio is 0.52 . It rises to 1.1 in the second quartile, 1.5 in the third and 2.1 in the richest quartile. Table 1 reports that a regression of this ratio on log GDP per capita yields an estimated slope coefficient always in the ballpark of 0.5 across all surveys, with little variation by data comparability tier. 


\subsection{Robustness}

In this section, we report how unemployment patterns vary by sex, age, and within rural and urban areas. Table 2 presents the slope coefficients from a regression of unemployment rates on log GDP per capita for various disaggregated categories of individuals. We do this separately for the low-education and high-education groups, first over all of our surveys (left panel), and then using only country averages over all available years (right panel).

Table 2: Robustness of Slope Coefficients of Unemployment Rate on log GDP per capita

\begin{tabular}{|c|c|c|c|c|c|c|}
\hline & \multicolumn{3}{|c|}{ All Surveys } & \multicolumn{3}{|c|}{ All Country Averages } \\
\hline & Low Edu. & High Edu. & $\mathrm{N}$ & Low Edu. & High Edu. & $\mathrm{N}$ \\
\hline Prime males & $\begin{array}{c}2.5^{* * *} \\
(.4)\end{array}$ & $\begin{array}{l}-.3 \\
(.3)\end{array}$ & 195 & $\begin{array}{c}2.9^{* * *} \\
(.6)\end{array}$ & $\begin{array}{l}.4 \\
(.3)\end{array}$ & 54 \\
\hline Full sample & $\begin{array}{c}3.3^{* * *} \\
(.4)\end{array}$ & $\begin{array}{l}-.5 \\
(.4)\end{array}$ & 197 & $\begin{array}{c}3.4^{* * *} \\
(.7)\end{array}$ & $\begin{array}{l}.5 \\
(.6)\end{array}$ & 54 \\
\hline Males & $\begin{array}{c}2.9^{* * *} \\
(.4)\end{array}$ & $\begin{array}{l}-.4 \\
(.3)\end{array}$ & 197 & $\begin{array}{c}3.1^{* * * *} \\
(.6)\end{array}$ & $\begin{array}{l}.4 \\
(.5)\end{array}$ & 54 \\
\hline Females & $\begin{array}{c}3.8^{* * *} \\
(.4)\end{array}$ & $\begin{array}{c}-.8^{*} \\
(.5)\end{array}$ & 197 & $\begin{array}{c}3.9^{* * *} \\
(.8)\end{array}$ & $\begin{array}{l}.3 \\
(.8)\end{array}$ & 54 \\
\hline Age 16-24 & $\begin{array}{c}6.2^{* * *} \\
(.7)\end{array}$ & $\begin{array}{c}-1.2 \\
(.8)\end{array}$ & 183 & $\begin{array}{c}6.6^{* * *} \\
(1.2)\end{array}$ & $\begin{array}{c}.5 \\
(1.3)\end{array}$ & 52 \\
\hline Age $25-54$ & $\begin{array}{c}2.9^{* * *} \\
(.4)\end{array}$ & $\begin{array}{l}-.2 \\
(.3)\end{array}$ & 195 & $\begin{array}{c}3.2^{\text {*** }} \\
(.6)\end{array}$ & $\begin{array}{l}.5 \\
(.4)\end{array}$ & 54 \\
\hline Age $55+$ & $\begin{array}{c}2.0^{* * *} \\
(.4)\end{array}$ & $\begin{array}{l}.5^{*} \\
(.2)\end{array}$ & 173 & $\begin{array}{c}2.4^{* * *} \\
(.6)\end{array}$ & $\begin{array}{l}.8^{*} \\
(.4)\end{array}$ & 49 \\
\hline Rural & $\begin{array}{c}2.7^{* * *} \\
(.6)\end{array}$ & $\begin{array}{c}-.02 \\
(.7)\end{array}$ & 107 & $\begin{array}{c}3.4^{* * *} \\
(1.0)\end{array}$ & $\begin{array}{l}1.8^{*} \\
(1.0)\end{array}$ & 29 \\
\hline Urban & $\begin{array}{c}2.5^{* * *} \\
(.9)\end{array}$ & $\begin{array}{l}-.9 \\
(.6)\end{array}$ & 107 & $\begin{array}{c}3.4^{* * *} \\
(1.2)\end{array}$ & $\begin{array}{l}.6 \\
(.8)\end{array}$ & 29 \\
\hline
\end{tabular}

Note: The table reports the slope coefficients from regressions of the unemployment rate on log GDP per capita and a constant. Observations include aggregate unemployment rates across all Tier 1, 2, and 3 surveys. Country averages are restricted to countries with at least two years' observations. ${ }^{* * *},{ }^{* *}$ and ${ }^{*}$ indicate statistical significance at the 1-percent, 5-percent and 10-percent levels.

The first row of Table 2 reports the slope for prime-aged males only. Across all surveys and country averages, low-educated prime-aged males have a statistically significant positive slope with GDP per capita, while high-educated ones have an insignificant slope. This pattern is 
replicated and even stronger in the full sample of households (second row), which includes household members aged 16 to 25, those above age 55, and both sexes. The patterns hold separately for males of all ages (third row) as well, while for females (fourth row), there is even a significant negative trend with GDP per capita among the high-educated. We conclude that our patterns hold for both sexes.

When looking by age group, the low-educated always have a significant and positive relationship with GDP per capita, with the strongest relationship for those aged 16 to 24 . The young high-educated have a significant negative slope with GDP per capita, at least across all surveys; the prime-aged have an insignificant negative trend; and the old have a small but significant positive slope. Thus, our patterns are robust across age groups. Finally, we look separately at rural and urban individuals. For both groups, we see the same patterns: strong positive increases in low-educated unemployment with GDP per capita and insignificant slopes for the high-educated. Thus, our findings are present in both rural and urban areas. ${ }^{6}$

\subsection{Employment, Unemployment, and Not in the Labor Force}

Other data sets show that average employment rates are lower in rich countries than in poor countries, at least for males (see e.g. Bick, Fuchs-Schuendeln, and Lagakos, 2018). Does this imply that unemployment rates are higher in rich countries? Basic accounting identities show that the answer is no. Those not employed can be either unemployed or not in the labor force. The lower employment rates of rich countries could in principle correspond to lower labor force participation rates, or higher unemployment rates, or both. In practice, we show that the relationship between employment rates, unemployment rates, the percent not in the labor force (NLF), and income per capita varies considerably by gender and education, and cannot be inferred directly from evidence on employment rates alone.

Table 3 reports the percent of prime aged adults - by sex and education level - that are employed, unemployed, and not in the labor force, for countries in the bottom and top income quartiles. For low-educated males, employment rates are substantially lower in the richest quartile than in the poorest. This reflects a substantially higher percent of low-educated males not in the labor force in the richest quartile, as well as their higher unemployment rates in the richest quartile. A similar pattern also holds for women, though with lower employment levels in both quartiles.

Among high-educated males, employment rates are modestly higher in the richest quartile

\footnotetext{
${ }^{6}$ One may worry that surveyors in poor countries may systematically avoid times when workers are unlikely to be unemployed, such as harvest times, so as to ensure adequate survey participation. If so, our surveys would overestimate the unemployment rates in the poor countries, thus, underestimating the slope of the relationship between average unemployment and income per capita.
} 
Table 3: Employment, Unemployment and Not in the Labor Force

\begin{tabular}{cccccccc} 
& & \multicolumn{3}{c}{ Low Education } & \multicolumn{3}{c}{ High Education } \\
\hline \multirow{3}{*}{ Male } & Income Quartile & Bottom & Top & Difference & Bottom & Top & Difference \\
\cline { 3 - 8 } & Employed & 87.5 & 72.8 & $-14.7^{* * *}$ & 83.1 & 86.3 & 3.2 \\
& Unemployed & 2.3 & 11.2 & $8.9^{* * *}$ & 4.0 & 6.1 & $2.1^{* * *}$ \\
& Not in labor force & 10.2 & 16.0 & $5.8^{*}$ & 12.9 & 7.6 & $-5.3^{* *}$ \\
\hline \multirow{2}{*}{ Female } & Employed & 60.4 & 46.0 & $-14.4^{*}$ & 63.1 & 69.7 & 6.6 \\
& Unemployed & 1.9 & 9.1 & $7.2^{* * *}$ & 4.2 & 6.7 & $2.4^{*}$ \\
& Not in labor force & 37.7 & 44.9 & 7.2 & 32.7 & 23.7 & $-9.0^{*}$ \\
\hline \hline
\end{tabular}

Note: This table reports summary statistics of prime age employment, unemployment and percent not in the labor force for the bottom and top quartile countries, by gender and education. The rows present the average of poor countries, the average of the rich countries, and the difference between the poor and rich means, plus the results of a permutation test of the differences in means.

than in the poorest quartile (though the difference is statistically insignificant). Yet the percent of high-educated males that are unemployed is also modestly higher in the richest quartile. The reason that both are higher in the richest quartile is that, as Table 3 shows, the percent not in the labor force is substantially lower for high-educated males in the richest quartile. A similar pattern again holds for females, though with larger increases in employment rates and labor force participation rates than for the males. We conclude that there is no simple way one can infer cross-country unemployment patterns by looking solely at data on employment rates, which reflect a margin of labor force participation as well.

\section{A Simple Model of Unemployment and Development}

In this section, we build a simple model to qualitatively match the increasing unemployment rate with development, and the patterns of unemployment by education level. Since the main focus of the paper is on unemployment rates, we abstract from the decision of whether to join the labor force. Since our empirical patterns are present for both sexes, all age groups and within both rural and urban areas, we abstract from demographics and regional considerations. In order to match the large decrease in the traditional (low-skilled self-employment) sector that coincides with development, we allow for two sectors in our model. 


\subsection{Environment}

There is a unit measure of risk-neutral, infinitely-lived workers, each of whom is endowed with efficiency units drawn from a fixed distribution $G(x)$ on $[\underline{x}, \bar{x}]$. We assume that $G(x)$ is differentiable and let $g(x) \equiv G^{\prime}(x)$ be its probability density function. There is also a continuum of risk-neutral, infinitely-lived firms, each of which can employ one worker. In this simple model, we assume undirected search in the aggregate distribution of ability. Later, in the quantitative version of our model, we relax these assumptions and allow firms to direct their search efforts toward high and low education groups of workers.

Workers can choose to work in one of two sectors: a traditional sector, in which workers are self-employed without returns to ability, and a modern sector, in which firms hire workers subject to matching friction. and production displays constant returns to ability. The technologies in the traditional and modern sectors, respectively, are given by:

$$
\begin{aligned}
Y_{T} & =A_{T} N_{T}, \quad \text { and } \\
Y_{M} & =A_{M} X_{M},
\end{aligned}
$$

where $Y_{T}, A_{T}$ and $N_{T}$ are output, productivity and the number of workers in the traditional sector, and $Y_{M}, A_{M}$ and $X_{M}$ are output, productivity and the total number of efficiency units in the modern sector. Countries vary in their level of productivity $A_{M}$ but not $A_{T}$, so technological change in our model is skill-biased. Here we assume the outputs of the modern and traditional sectors to be perfect substitutes for simplicity. We relax this assumption and the invariance of $A_{T}$ in the quantitative model that follows. Our assumption of exogenous modern-sector productivity is abstract, though it may capture more concrete channels that affect firm size and hence the extent of wage employment, such as firm financial frictions (e.g. Banerjee and Newman, 1993; Buera, Kaboski, and Shin, 2011; Greenwood, Sanchez, and Wang, 2010), or monitoring frictions (e.g. Akcigit, Alp, and Peters, 2018; Cole, Greenwood, and Sanchez, 2016).

We now combine a Diamond-Mortensen-Pissarides model of steady-state unemployment with a Roy model of selection into the modern versus the traditional sector.

Steady State. In the steady state, workers will not move between sectors in the absence of shocks. Denote by $x^{*}$ the efficiency units of the marginal worker who is indifferent between self-employment and entering the modern sector unemployed. We will show below that the value of being unemployed is increasing in $x$; hence, in steady state, workers with $x<x^{*}$ prefer self-employment in the traditional sector, and workers with $x \geq x^{*}$ prefer to enter the modern sector as unemployed. 
Modern Sector. In order to hire a worker, a firm must post a vacancy at flow cost $A_{M} c .^{7}$ Let the flow of matches be given by the constant returns to scale function

$$
m(u, v)=\eta u^{\alpha} v^{1-\alpha}
$$

where $u$ is the endogenous measure of unemployed workers and $v$ is the endogenous measure of vacancies in the economy. Define $\theta \equiv \frac{v}{u}$ as "market tightness." The job-finding rate is then $f(u, v) \equiv \frac{m}{u}=\eta \theta^{1-\alpha}$, and the vacancy hiring rate is $q(u, v) \equiv \frac{m}{v}=\eta \theta^{-\alpha}$.

We assume that workers and firms separate at an exogenous rate $s$. Let $A_{M} b x$ denote the unemployment flow payoff, ${ }^{8}$ where $0<b<1$. One rationale for this choice is that unemployment benefits are typically indexed to wages, which we will show scale with $A_{M} x$ in equilibrium. A second rationale is that job finding rates are approximately constant across skill groups, which is consistent with a model where unemployment benefits scale with the expected wage (Hall and Mueller, Forthcoming; Mincer, 1991; Mueller, 2017). Denoting by $\delta$ the rate of time discount for all agents, the values of unemployment and employment for an individual with efficiency units $x$ are given, respectively, by

$$
\begin{aligned}
& U(x)=A_{M} b x+\delta[f E(x)+(1-f) U(x)] \\
& E(x)=w(x)+\delta[s U(x)+(1-s) E(x)]
\end{aligned}
$$

where $w(x)$ is the endogenous flow wage.

Because firms will be matched only with agents in the modern sector, who have efficiency units $x \geq x^{*}$, we can specify the value of a job to a firm if matched with a worker with efficiency units $x$ and the value of maintaining a vacancy as:

$$
\begin{aligned}
J(x) & =A_{M} x-w(x)+\delta[s V+(1-s) J(x)] \\
V & =-A_{M} c+\delta\left[q \mathbb{E}\left(J \mid x>x^{*}\right)+(1-q) V\right],
\end{aligned}
$$

where $\mathbb{E}\left(J \mid x>x^{*}\right)=\frac{\int_{x^{*}}^{\bar{x}} J(x) g(x) d x}{1-G\left(x^{*}\right)}$ is the expected value to the firm of a job match conditional on the workers having entered the modern sector.

Because of the free-entry condition for firms, we have $V=0$. Let $S(x) \equiv E(x)-U(x)+J(x)$ denote the total surplus of a match, and $\beta \in(0,1)$ be the Nash bargaining power of the worker. The firm then receives $(1-\beta) S(x)$ when a vacancy is filled. Combining this division of the surplus with equations (4) to (7) allows us to solve for $U(x)$ and $w(x)$, with the former

\footnotetext{
${ }^{7}$ We shall see later that, in equilibrium, wages scale with $A_{M}$. If the productivity of the vacancy posting process is not affected by $A_{M}$, the cost of posting a vacancy should also scale with $A_{M}$.

${ }^{8}$ Our results are qualitatively unchanged if we let $A_{M} b$ denote the unemployment flow payoff.
} 
given by:

$$
U(x)=\frac{1}{1-\delta}\left(A_{M} b x+\delta \eta \theta^{1-\alpha} \frac{\beta}{1-\beta} \frac{A_{M} x(1-b)(1-\beta)}{\beta \delta \eta \theta^{1-\alpha}+1-\delta+\delta s}\right) .
$$

Equation (8) shows that $U(x)$ is increasing, as we asserted previously. We also show in Appendix B.1 that steady state in the modern sector is characterized by the following relationship between $\theta$ and $x^{*}$ :

$$
c=\frac{(1-\beta) \delta \eta \theta^{-\alpha}}{\beta \delta \eta \theta^{1-\alpha}+1-\delta+\delta s}(1-b) \mathbb{E}\left(x \mid x>x^{*}\right) .
$$

Note that market tightness $\theta$ is unaffected by $A_{M}$ for a given $x^{*}$. By equation (11) below, this implies that unemployment is unaffected by $A_{M}$ for a given $x^{*}$. Thus, in the absence of a traditional sector, our model predicts that unemployment remains constant as per capita income increases. If $b$ or $c$ did not scale with $A_{M}, \theta$ would instead decrease with $A_{M}$ for a given $x^{*}$, and in the absence of a traditional sector, our model would predict that unemployment decreases as per capita income increases.

Indifference Condition. The value of staying in the traditional sector is $\frac{A_{T}}{1-\delta}$, since any traditional worker produces $A_{T}$ in every period. The worker with efficiency units $x^{*}$ is indifferent between staying in the traditional sector and entering the modern sector as unemployed:

$$
\frac{A_{T}}{1-\delta}=U\left(x^{*}\right)=\frac{1}{1-\delta}\left(A_{M} b x^{*}+\delta \eta \theta^{1-\alpha} \frac{\beta}{1-\beta} \frac{A_{M} x^{*}(1-b)(1-\beta)}{\beta \delta \eta \theta^{1-\alpha}+1-\delta+\delta s}\right) .
$$

Unemployment Rate. Letting $u_{M}$ denote the measure of the modern-sector unemployed and its steady-state value, we can write the change in modern-sector unemployment as $\dot{u}_{M}=\left(L_{M}-u_{M}\right) s-u_{M} f(\theta)$, where $f(\theta)=\eta \theta^{1-\alpha}$ is the steady state job finding rate and $L_{M}=1-G\left(x^{*}\right)$ is the labor that participates in the modern sector. We can then set $\dot{u}_{M}=0$ to obtain the measure of steady-state modern sector unemployment, which is the same as the overall unemployment rate, since the overall measure of workers is one and there is no unemployment in the traditional sector:

$$
u=\frac{s\left(1-G\left(x^{*}\right)\right)}{s+\eta \theta^{1-\alpha}}
$$

Note that the unemployment rate depends on the separation rate, $s$, the (endogenous) market tightness, $\theta$, and the (endogenous) cutoff $x^{*}$ for working in the modern sector. The fraction $1-G\left(x^{*}\right)$ represents the measure of workers in the modern sector. The higher is this fraction, all else equal, the higher is the unemployment rate. Similarly, the lower is $\theta$, all else equal, the higher is unemployment. 


\subsection{Model Solution and Predictions}

We now establish the uniqueness of our model solution, and characterize how the endogenous variables $\theta$ and $x^{*}$ vary with modern-sector productivity, $A_{M}$.

Proposition 1 If an interior solution $x^{*} \in(\underline{x}, \bar{x})$ exists, the model solution $\left(x^{*}, \theta\right)$ is unique, and the cutoff ability $x^{*}$ decreases as modern-sector productivity $A_{M}$ increases.

Proof. See Appendix B.2.

Proposition 1 shows that an increase in modern sector productivity reduces $x^{*}$, drawing workers out of the traditional sector into the modern sector. This result plays an important role in determining how unemployment rates vary with modern-sector productivity. In particular, we can use it to help establish:

Proposition 2 The aggregate unemployment rate $u$ increases as modern-sector productivity $A_{M}$ increases.

Proof. See Appendix B.3.

The intuition for this result is as follows. First, as $A_{M}$ increases, workers are drawn out of the traditional sector and into search for wage employment in the modern sector, as shown in Proposition 1. Because modern-sector jobs involve regular separations, a larger modern sector means larger steady-state unemployment, all else equal. Second, as $A_{M}$ increases, market tightness, $\theta$, falls in equilibrium. Because the workers drawn into the modern sector are of lower ability than existing modern-sector workers, the expected value of a match to the firm falls. For the free-entry condition to hold, the job filling rate for a vacancy must rise. This means fewer vacancies per unemployed person, i.e., a smaller $\theta$.

Proposition 3 Let $x^{*}$ be an interior solution and $x_{0}<x^{*}$ denote a fixed ability level. Then the ratio of the unemployment rate for workers with ability lower than $x_{0}$ to that of workers with ability higher than $x_{0}$ increases as modern-sector productivity $A_{M}$ increases.

Proof. See Appendix B.4.

In short, this result states that the relative unemployment of less-able to more-able workers increases with development. Intuitively, this occurs because a larger share of less-able workers are drawn into the modern sector as $A_{M}$ rises. Figure 4 illustrates how Proposition 3 works. Denote the "high-ability workers" as those with ability above $x_{0}$, and those below $x_{0}$ as the "low-ability workers." The initial cutoff is depicted as $x_{1}^{*}$, and hence regions $A$ and $B$ represent the traditional sector, whereas $C$ and $D$ are the modern sector. Once $A_{M}$ rises, the cutoff falls, by Proposition 1 , to a lower cutoff which we denote by $x_{2}^{*}$. Region B switches from the traditional to the modern sector. Since these are low-ability workers, and no high-ability workers switch sectors, the ratio of low- to high-ability unemployment increases. 
Figure 4: Comparative Statics in $A_{M}$ in Simple Model

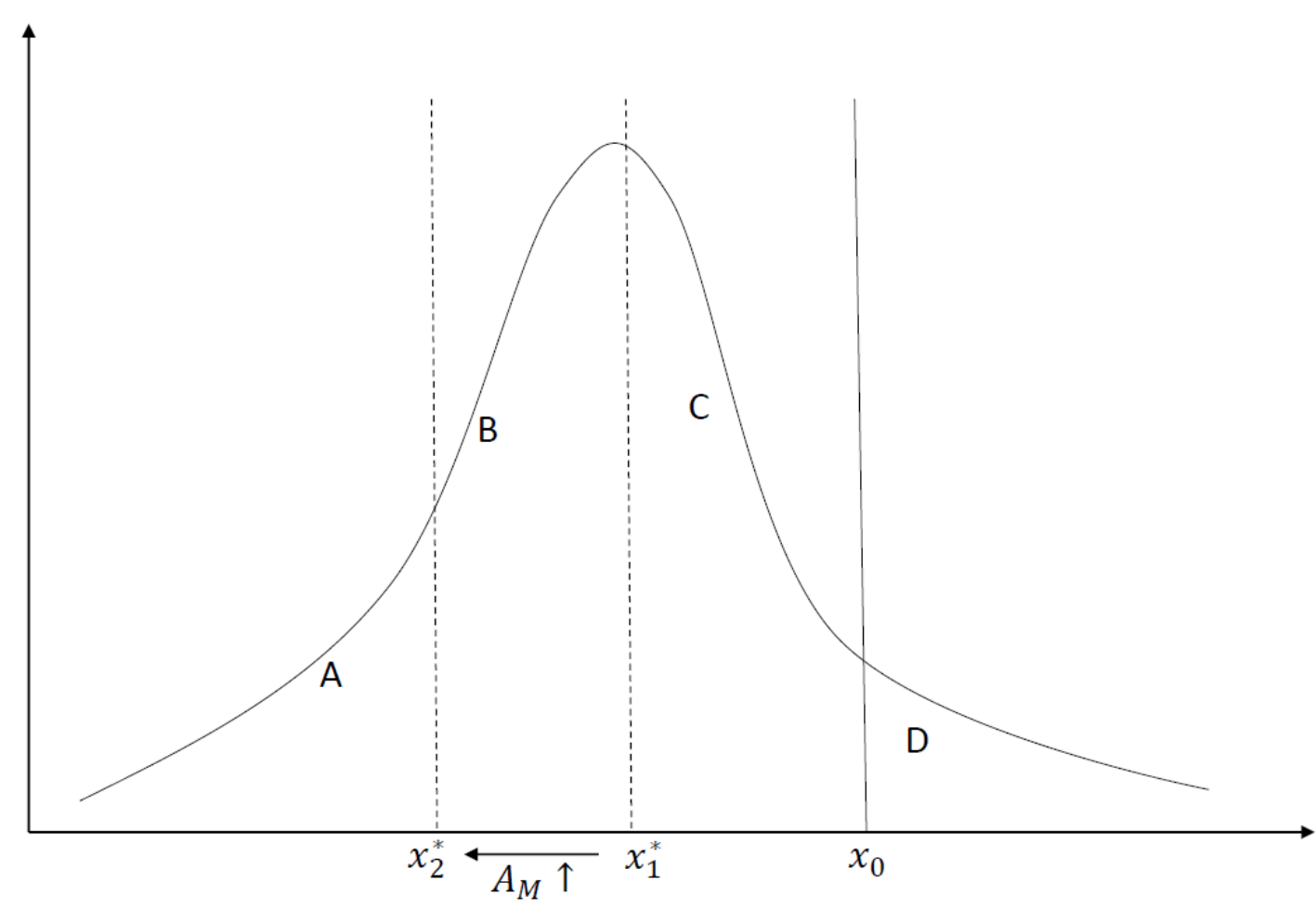

Note: This figure illustrates comparative statics in $A_{M}$, characterized formally in Propositions 2 and 3.

\section{Quantitative Analysis}

Though the simple model above is useful for establishing the qualitative properties of our theory, the model is a bit too stylized to use in our quantitative analysis. Thus, in this section we build a richer quantitative version of the model. We then calibrate the model to match features of the U.S. labor market, and compute the model's predictions over the full range of the world income distribution.

\subsection{Quantitative Version of the Model}

In our simple model the outputs of the modern and traditional sectors are perfect substitutes, so their relative price cannot change as $A_{M}$ rises. This is at odds with the well-known tendency for the relative price of non-traded services, in which the traditional sector is intensive, to rise with per capita GDP. With this in mind, we now allow traditional and modern sector outputs to be imperfect substitutes. We specify the following constant-elasticity-of-substitution (CES) aggregate production function:

$$
Y=\left(\gamma Y_{T}^{\sigma}+(1-\gamma) Y_{M}^{\sigma}\right)^{\frac{1}{\sigma}}
$$


where $Y_{T}$ and $Y_{M}$ are the aggregate outputs of the traditional and modern sectors, respectively, and the elasticity of substitution between them equals $\frac{1}{1-\sigma}$. Denote the price of traditionalsector output relative to modern-sector output by $P_{T}$. In a competitive market, the ratio of prices equals the ratio of marginal productivities:

$$
P_{T}=\frac{\partial Y / \partial Y_{T}}{\partial Y / \partial Y_{M}}=\frac{\gamma}{1-\gamma}\left(\frac{Y_{M}}{Y_{T}}\right)^{1-\sigma} .
$$

Technological change that is skill-biased across countries is a core assumption of our model. The assumption that technological change in the traditional sector is zero, however, is an oversimplification. In our quantitative exercise we allow for an elasticity of technological change in the traditional sector with respect to technological change in the modern sector that is less than one. Specifically, in our calibration procedure we will assume that $\log \left(A_{T}\right)=$ $\theta_{0}+\theta_{1} \log \left(A_{M}\right)$, where we expect to find that $\theta_{1}<1 .^{9}$

Increases in $P_{T}$ or $A_{T}$ with $A_{M}$ cause workers who remain in the traditional sector in rich countries to earn more than traditional sector workers in poor countries. This is more realistic than the prediction of the simple model that earnings of traditional sector workers in rich and poor countries will be the same.

Key predictions of our model concern traditional employment and unemployment by worker ability. Unfortunately, direct measures of ability across many countries are not available. Wage is a linear function of ability in our model, but we cannot observe wages for the self-employed in the traditional sector or the unemployed. Instead, for the purpose of quantifying our predictions regarding traditional self-employment and unemployment by ability, we use education as our proxy for ability. Specifically, we divide the labor force into the two education groups used above, in particular the low education group, which did not finish secondary school, and the high education group, which completed secondary school or more. We incorporate education into our model as a proxy for ability by assuming that the distribution of ability for the high-education group first-order stochastically dominates the distribution of ability for the low-education group: $G_{h}(x)<G_{l}(x)$ for all $x \in(\underline{x}, \bar{x}) .{ }^{10}$

Countries differ exogenously in the fraction $\lambda$ of their workers that are in the low-education group. The remaining $1-\lambda$ are in the high-education group. We assume employers can

\footnotetext{
${ }^{9}$ In our theory, the higher relative output of goods produced by skilled workers that occurs with development results only from increased productivity in the modern sector relative to the traditional sector. In reality, however, development leads to an increase in the relative demand for skill-intensive goods, as richer households demand more skill-intensive products and services (Buera and Kaboski, 2012; Buera, Kaboski, and Rogerson, 2015) Our results would still apply, at least qualitatively, if we were to extend our model to include nonhomothetic preferences in which higher income causes higher relative demand for skill-intensive goods.

${ }^{10}$ This condition is sufficient, but not necessary, for the results of this subsection. We verified that the distributions calibrated in the next subsection satisfy this condition.
} 
observe this education credential ex ante and divide the modern sector labor market into two search markets, one for each education level. Finally, we treat the outputs of modern-sector firms that search in the high-education and low-education labor markets as perfect substitutes, and add them to obtain $Y_{M}$ in equation (13).

We also allow for the possibility that the separation rate for high-educated workers is less than for low-educated workers, though this is not necessary to obtain any of our qualitative results: $s_{h} \leq s_{l}$. All other parameters are assumed to be the same across the two labor markets.

We can now prove:

Lemma 1 For any interior solution to the model with two labor markets, $x_{h}^{*}<x_{l}^{*}$.

Proof. See Appendix B.5.

It follows from Lemma 1 and $G_{h}(x)<G_{l}(x)$ that the share of high-educated agents who are self-employed in the traditional sector is lower than the corresponding share of low-educated agents:

Proposition 4 For any interior solution to the model with two labor markets, $G_{h}\left(x_{h}^{*}\right)<$ $G_{l}\left(x_{l}^{*}\right)$.

As modern sector productivity $A_{M}$ increases in our simple model, Proposition 1 states that the share of workers who are self-employed in the traditional sector falls ( $x^{*}$ decreases). Similarly, if increasing $A_{M}$ dominates increasing traditional sector relative price $P_{T}$ and traditional sector productivity $A_{T}$ in our quantitative model, the shares of both high- and low-educated workers who are self-employed in the traditional sector will fall $\left(x_{h}^{*}\right.$ and $x_{l}^{*}$ both decrease). The unemployment rates of both high- and low-educated workers must then increase, just as did the aggregate unemployment rate in the simple model (Proposition 2 ). Here, however, the aggregate unemployment rate does not necessarily increase, despite increases in the unemployment rates for both education groups. The aggregate unemployment rate in the quantitative version of our model is a weighted average of the unemployment rates of high- and low-educated workers, with weights $1-\lambda$ and $\lambda$. In the data, as modern sector productivity and thus GDP per capita increases, the share of low-educated workers $\lambda$ tends to decrease. If the high-educated unemployment rate is smaller than the low-educated unemployment rate, it is possible for the aggregate unemployment rate predicted by the quantitative version of our model to decrease with $A_{M}$ and GDP per capita.

Whether the ratio of low-educated to high-educated unemployment rates increases with $A_{M}$ in the quantitative model, which would be the equivalent of Proposition 3 in the simple model, depends on the calibration. However, we can establish a strong presumption that our quantitative model will display this property. The basis for Proposition 3 is that, as 
$A_{M}$ increases, participation in the modern sector by workers with low ability increases relative to participation by workers with high ability. We can expect, similarly, that as $A_{M}$ increases, participation in the modern sector of low-educated workers will increase proportionately faster than participation of high-educated workers. The reason is that loweducated workers' participation in the modern sector must be lower according to Proposition 4 , but both participation rates must approach 100 percent as $A_{M}$ increases. In our quantitative predictions in Subsection 5.3 below, participation of low-educated relative to high-educated workers in the modern sector does indeed increase as $A_{M}$, and thus per capita GDP, increases.

\subsection{Parameterizing the Model}

We begin by directly setting some parameter values following the literature. We set the quarterly discount factor to $\delta=0.99$, consistent with an annual interest rate of around four percent. We set the worker's bargaining weight to $\beta=0.7$ and the elasticity parameter of the matching function to $\alpha=0.7$, which are the values used in Fujita and Ramey (2012) and are in line with the standard parameter choices used in macro search models. We set the quarterly separation rate for the high-educated workers to $s_{h}=0.045$, which is the value estimated in Wolcott (2018). We use the unemployment benefits replacement rate of 45 percent. This is in line with the 40 percent used by Shimer (2005), the 42 percent in Braxton, Herkenhoff, and Phillips (2018), and the 50 - 60 percent range in Krueger and Mueller (2010). We also normalize the mean of the ability for low-educated workers to be one.

We set the elasticity of substitution between traditional and modern goods to be 3 in our benchmark calibration, though we explore sensitivity to this parameter, as we describe below. Our elasticity of substitution relates to some extent to the elasticity of substitution between home and market goods that is emphasized by the large literature emphasizing home production in the macroeconomy. ${ }^{11}$ Though our model's elasticity is related to these, it is not exactly comparable, and one may imagine that there are greater substitution possibilities between modern and traditional goods than between home and market production, since modern and traditional goods are both purchased in the market. For example, one type of substitution between the modern and traditional sector may be getting older shoes shined

\footnotetext{
${ }^{11}$ See eg. Baxter and Jermann (1999); Benhabib, Rogerson, and Wright (1991); Greenwood and Hercowitz (1991); Karabarbounis (2014); Ngai and Pissarides (2008, 2011); Rogerson (2008). Aruoba, Davis, and Wright (2016) choose a value of 1.8 , and argue that this is close to the midpoint of the range suggested by previous estimates in this literature. For example, Rupert, Rogerson, and Wright (1995) use panel data from the PSID with evidence on time spent in home production and market work, and estimate an elasticity of substitution between 1.8 and 2.0. McGrattan, Rogerson, and Wright (1997) and Chang and Schorfheide (2003) use U.S. time series data and come up with estimates of 1.5 to 1.8 and 2.3 respectively. Aguiar and Hurst (2007a) draw on detailed household-level data on market goods consumption and time spent on home production, such as cleaning, cooking and home repair. They estimate an elasticity of substitution of 2.1 when considering all home production categories in their data.
} 
and repaired (from a self-employed shoe repairer) rather than purchasing newer shoes (from a modern shoe factory). Another example is buying produce from an informal road-side vendor versus buying produce at a modern supermarket. It is therefore worth looking at alternative evidence on substitution between different categories of purchased goods and services. In a widely cited study, Broda and Weinstein (2006) estimate elasticities of substitution across a diverse set of goods varieties, finding a median estimate of around 2.2 to 3.7 across goods categories. ${ }^{12}$ Our benchmark value of 3 is right in the middle of their estimates, though since there is not a more precise value suggested by the literature, we explore a lower value of 2.5, closer to the home-production literature, and a higher value of 3.5, close to the upper end of the values estimated by Broda and Weinstein (2006).

We calibrate the remaining eight parameters to jointly match eight moments in the data. These parameters are: (i) the mean of the ability distribution for the high-educated workers, $m_{h}$; (ii) and (iii): the variances of the ability distributions for the low- and high-educated workers, $v_{l}$ and $v_{h}$; (iv) the vacancy cost $c$ as a share of the modern-sector productivity for a worker with one unit of ability; (v) the efficiency term, $\eta$, of the matching function; (vi) the traditional-sector share in the aggregate production function, $\gamma$; (vii) the quarterly separation rate for the low-educated workers, $s_{l}$; and, finally, (viii): the maximum value of $A_{M}$, which corresponds to the U.S. level. ${ }^{13}$

The eight moments are: (i) the ratio of the average modern-sector wages for the high- over low-educated that we calculated using the 2000 Census $5 \%$ sample (1.60); (ii) and (iii) the variances of log wages for the high- and low-educated (0.34 and 0.28), using the same 2000 census; (iv) the vacancy cost of 17 percent of average output in the modern sector as used in Fujita and Ramey (2012); (v) the average U.S. unemployment rate of 5.71 percent in the United States among the 18 samples in our data from 1960 to 2014; (vi) the U.S. expenditure share in the traditional sector, which we conjecture to be smaller than two percent; (vii) the ratio of unemployment for the the low-educated to high-educated (2.31); and (viii) an average employment share of two percent in the traditional sector (as we explain below).

We define the traditional sector as the intersection of own-account (self-employed without employees) workers and occupations with low skill content - in particular, shop and market sales, agricultural and fishery workers, crafts and related trades workers, plant and machine

\footnotetext{
${ }^{12}$ We are not aware of any estimates of substitution elasticities between goods with low and high levels of skill inputs. On the production side, the closest estimate would be for the substitution elasticity between highand low-skilled labor in the aggregate production function; Autor (2002, pg. 11) argues that the "consensus across estimates for the U.S." is that this elasticity is approximately two. McKiernan (2018) estimates an elasticity of substitution of around 6.5 between informal and formal labor, though this is again about production and not final consumption goods.

${ }^{13}$ Note that although the absolute value of $A_{M}$ is smaller than $A_{T}$, the modern sector is more productive than the traditional sector in value terms. The traditional and modern sectors produce different goods, and the relative price of the traditional good, $P_{T}$, is around 0.01 in the United States in our calibrated model.
} 
Table 4: Calibrated Parameters

\begin{tabular}{|c|c|}
\hline Parameter & Value \\
\hline \multicolumn{2}{|l|}{ Panel A: Pre-Assigned Parameters } \\
\hline$\delta$ - Discount factor (quarterly) & 0.99 \\
\hline$\beta$ - Workers' bargaining power & 0.7 \\
\hline$\alpha$ - Matching parameter & 0.7 \\
\hline$s_{h}$ - Separation rate (quarterly) for high-educated workers & 0.045 \\
\hline$b$ - Unemployed benefits & 0.45 \\
\hline$\frac{1}{1-\sigma}-$ Elasticity of substitution & 3 \\
\hline$A_{T(U S)}$ - U.S. traditional-sector productivity & 1 \\
\hline$m_{l}$ - Mean of ability dfor low-educated workers & 1 \\
\hline \multicolumn{2}{|l|}{ Panel B: Calibrated Parameters } \\
\hline$m_{h}$ - Mean of ability for high-educated workers & 1.66 \\
\hline$v_{l}$ - Variance of ability for low-educated workers & 0.45 \\
\hline$v_{h}$ - Variance of ability for high-educated workers & 1.15 \\
\hline$c$ - Vacancy cost & 0.15 \\
\hline$\eta$ - Matching efficiency & 0.85 \\
\hline$\gamma$ - Traditional-sector share in aggregate production function & 0.01 \\
\hline$s_{l}-$ Separation rate (quarterly) for low-educated workers & 0.112 \\
\hline $\max \left(A_{M}\right)$ - Modern-sector productivity for the richest country & 0.04 \\
\hline
\end{tabular}

Note: The table reports the values and interpretations of the parameters of the quantitative model under the benchmark calibration.

operators and assemblers, and "elementary occupations." Unfortunately, the U.S. data after 1960 distinguish only between incorporated and unincorporated businesses among the self-employed, rather than between own-account workers and employers as in the countries in Figures 5 and 6 below. Considering that the Canada samples have an average of 2.8 percent prime-aged employment in the traditional sector, which is defined consistently with the other countries, we conjecture that the United States has a smaller share of two percent. As with our benchmark unemployment measures, all traditional sector employment shares reported in this section are calculated for prime-aged workers.

Table 4 reports the value of each parameter used in the calibration. Our calibrated quarterly separation rate for the low-educated is 0.112 , similar to the direct estimate of $0.06-0.12$ 
Table 5: Moments Targeted in the Model vs Data

\begin{tabular}{lcc}
\hline \hline Moment & Target & Model \\
\hline Ratio of average wage for the high- vs low-educated & 1.60 & 1.61 \\
High-edu $\log$ (wage) variance & 0.34 & 0.33 \\
Low-edu $\log$ (wage) variance & 0.28 & 0.28 \\
U.S. vacancy cost as \% of average output in modern sector & 17 & 16.9 \\
U.S. unemployment rate & 5.71 & 5.69 \\
U.S. \% expenditure share of traditional sector & $<2.0$ & 0.67 \\
U.S. ratio of unemployment rates $u_{l} / u_{h}$ & 2.31 & 2.32 \\
U.S. traditional sector employment share & 2 & 1.84 \\
\hline \hline
\end{tabular}

Note: The table reports the moments targeted in the benchmark calibration of the quantitative model and the model's predictions for each moment.

during 1980 to 2010 computed by Wolcott (2018) for low-educated workers. Our estimate is also broadly consistent with the separation rate in low-skilled services in the United States. For example, according to the 2017 Job Openings and Labor Turnover Survey, the monthly separation rate in wholesale and retail trade, transportation and utilities is around 3.5 percent. This corresponds to a quarterly separation rate of around 10 percent.

We report each moment and its model counterpart in Table 5. Overall, the model matches the desired moments quite well. Although all of the eight parameters reported above jointly discipline all the parameters, it is useful to provide some intuition about which moments are most informative about each parameter. In particular, the mean of the ability distribution for high-educated workers, $m_{h}$, largely governs the ratio of average wage of the high- to low-educated workers. The variances of the two ability distributions govern the variances of log wages for the low- and high-educated workers. The model vacancy cost and model unemployment benefit are most informative about the relative size of vacancy cost and unemployment benefits to the average output per worker in the modern sector. The matching efficiency parameter $\eta$ mostly informs the average unemployment rate, and the sector share parameter in the aggregate production function mostly informs the expenditure share of traditional-sector output. The quarterly separation rate for low-educated workers is most informative about the unemployment ratio of low- to high-educated workers. Finally, the maximum $A_{M}$ value governs the traditional sector employment share in the richest country (the United States). 
Table 6: Slope of Log Relative Prices on $\log (\mathrm{GDP})$ in Data

\begin{tabular}{lc|lc}
\hline \hline Shoe repair - women's street shoes & $\begin{array}{c}.39^{* * *} \\
(.002)\end{array}$ & Men's basic haircut & $\begin{array}{c}.61^{* * *} \\
(.001)\end{array}$ \\
Shoe repair - men's classic shoes & $\begin{array}{c}.53^{* * *} \\
(.004)\end{array}$ & Ladies haircut - curlers & $\begin{array}{r}.63^{* * *} \\
(.002)\end{array}$ \\
Shoeshine & $\begin{array}{c}.56^{* * *} \\
(.002)\end{array}$ & Manicure & $\begin{array}{r}.44^{* * *} \\
(.003)\end{array}$ \\
& $\begin{array}{c}.42^{* * *} \\
(.006)\end{array}$ & Ladies haircut - long hair & $\begin{array}{c}.68^{* * *} \\
(.002)\end{array}$ \\
\hline \hline
\end{tabular}

Note: Data come from the unpublished ICP 2011 disaggregated price data for the Global Core list of goods and services. See Appendix Table $\mathrm{C} 1$ for the exact definition of each good and service. The table reports the slope coefficient from a regression of the log of the item price relative to the investment goods price on $\log$ GDP per capita and a constant. ${ }^{* * *},{ }^{* *}$ and $*$ indicate statistical significance at the 1-percent, 5 -percent and 10-percent levels.

It remains to calibrate the elasticity of traditional sector productivity with respect to modern sector productivity. To do so, we use the fact that greater increases in $A_{T}$ will result in smaller increases in $P_{T}$ as GDP per capita increases, all else equal. Specifically, we target the elasticity of the relative price of traditional goods with respect to GDP per capita.

We draw on disaggregated evidence on average national prices for specific products from the 2011 International Comparison Program (ICP). The ICP data are the best available data on the prices of identical (or nearly identical) goods and services around the world, and are available for almost every country in the world. How do we define traditional goods in these data? Consistent with our definition of the traditional sector, we pick goods or services that are have low skill content and are likely to be provided by self-employed workers. We identified eight specific services that plausibly meet these criteria: (i) a shoe repair for women's street shoes; (ii) a shoe repair for men's classic shoes; (iii) a shoeshine; (iv) a $7 \mathrm{~km}$ taxi ride from the town center; (v) a men's basic haircut; (vi) a ladies haircut with curlers; (vii) a manicure; (viii) a ladies haircut, long hair. Appendix Table $\mathrm{C} 1$ provides the exact definitions of these eight traditional sector services. Since investment goods largely fit our definition of a modern output, we take the aggregate price level of investment from the Penn World Table as a proxy for our modern sector price. For each traditional-sector service, we then compute the relative price of the service compared to investment goods in each country. Table 6 reports the slope coefficient from a regression of the log of the item relative price on $\log$ GDP per capita and a constant. As shown in the table, the elasticity of the relative price ranges between 0.39 to 0.68 . We target the median of these relative price elasticities, which 
is around 0.60. Our calibration uses the parameter $\theta_{1}$, the elasticity of $A_{T}$ with respect to $A_{M}$, to target this relative price elasticity. This yields $\theta_{1}=0.26$, with the intercept $\theta_{0}$ in the equation $\log \left(A_{T}\right)=\theta_{0}+\theta_{1} \log \left(A_{M}\right)$ determined implicitly by our normalization of $A_{T}$ to be one in the United States. ${ }^{14}$

\subsection{Quantitative Predictions}

With the model calibrated to the U.S. data, we then lower $A_{M}, A_{T}$, and $\lambda$, the fraction of workers that are low-educated. We discipline $\lambda$ directly using data on the fraction of workers with less than high school education across our set of countries (see Appendix Figure C1). After solving each economy, we use the equilibrium prices $P_{T}$ from all economies to compute a single international price, the average of $P_{T}$ weighted by traditional-sector output in each economy. We use this international price to compute the values of model outputs for all economies, including the U.S., and then scale all output values such that the richest economy matches the U.S. GDP per capita of $\exp (10.7)$ or $\$ 44,355$.

Figure 5 plots the traditional-sector size in the model and data. As GDP per capita decreases from the U.S. level, our model predicts an increase in the traditional-sector size from two percent to almost 60 percent. This is largely in line with our data. Furthermore, our model gets the curvature largely correct - in particular, the convex relationship between traditionalsector share and GDP per capita. This occurs partly because in richer economies almost all high-educated workers in the model are in the modern sector, so when those workers start to switch to the traditional sector, its size increases faster.

To emphasize the mechanisms further, Figure 6 plots the traditional-sector shares by education level. As in the data, the model predicts decreasing relationships between the traditional sector shares and per capita GDP for both groups. Crucially, it predicts much higher shares of traditional sector employment for the low-educated in poor countries. As $A_{M}$ rises, there are more low- than high-educated workers to sort out of the traditional sector, and as a result unemployment rises more for the low-educated (as in the data). This differential rate of exodus from the traditional sector as $A_{M}$ rises is thus key to our theory, and Figure 6 shows that the magnitudes here are largely consistent with the data. Note that the aggregate traditional-sector share in Figure 5 is nearly the same as the low-educated traditional sector share in Figure 6, because the labor force in poor countries is dominated by low-educated workers.

Figure 7 plots the aggregate unemployment level in the model and data. As GDP per capita

\footnotetext{
${ }^{14}$ Specifically, to match the elasticity of relative price to GDP per capita, we have to solve the full set of countries in the model with potential values of $\theta_{1}$. In contrast, we only need to solve one country in the model to calibrate the eight U.S. moments.
} 
Figure 5: Traditional-Sector Share in Model and Data

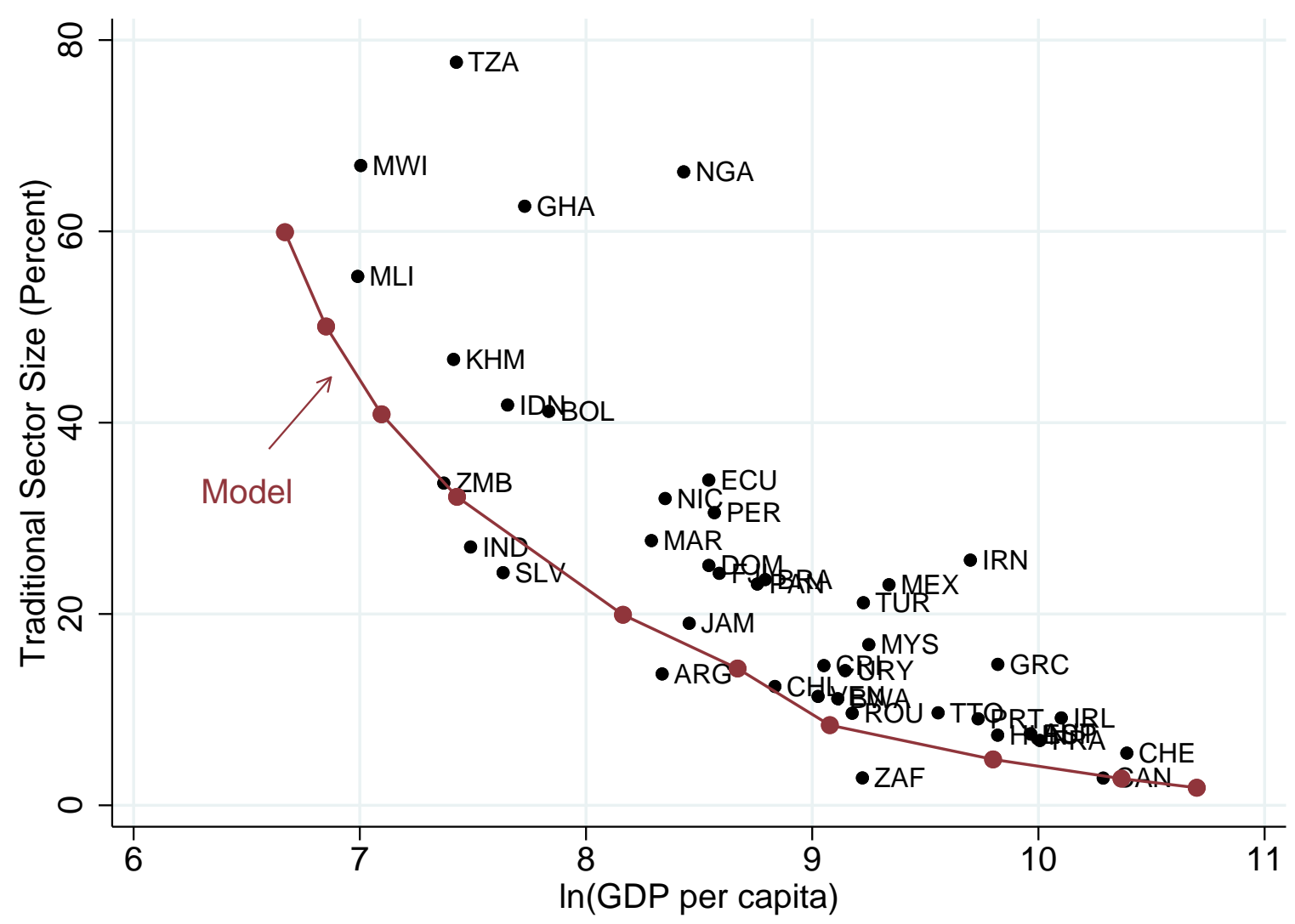

Note: This figure plots the size of the traditional sector against log GDP per capita in the data and model. Each dot represents one country, and the solid line is the prediction of the quantitative model.

increases, our model predicts that the unemployment rate will increase from less than 4 percent to the calibrated value of 5.7 percent. This is similar to the magnitudes in the data, though the model somewhat under-predicts the steepness of the relationship. Further, consistent with the data, our model predicts a sharper increase when GDP per capita is lower. This is a result of the faster decrease in the traditional-sector share when GDP per capita is lower.

Figure 8 plots the ratio of unemployment for the low-educated to the high-educated in the model and data. The model is calibrated to obtain the correct ratio for the United States. For lower levels of GDP per capita, the model predicts a decline in this ratio, as in the data. Again, the the model underpredicts the steepness of this relationship. The model predicts that this ratio is just above one for the poorest countries, whereas in the data, the ratio is closer to 0.5 .

Table 8 reports the slope coefficients from regressions of the unemployment rate and other key variables for prime age workers on log GDP per capita and a constant, in our model and 
Figure 6: Traditional-Sector Share by Education
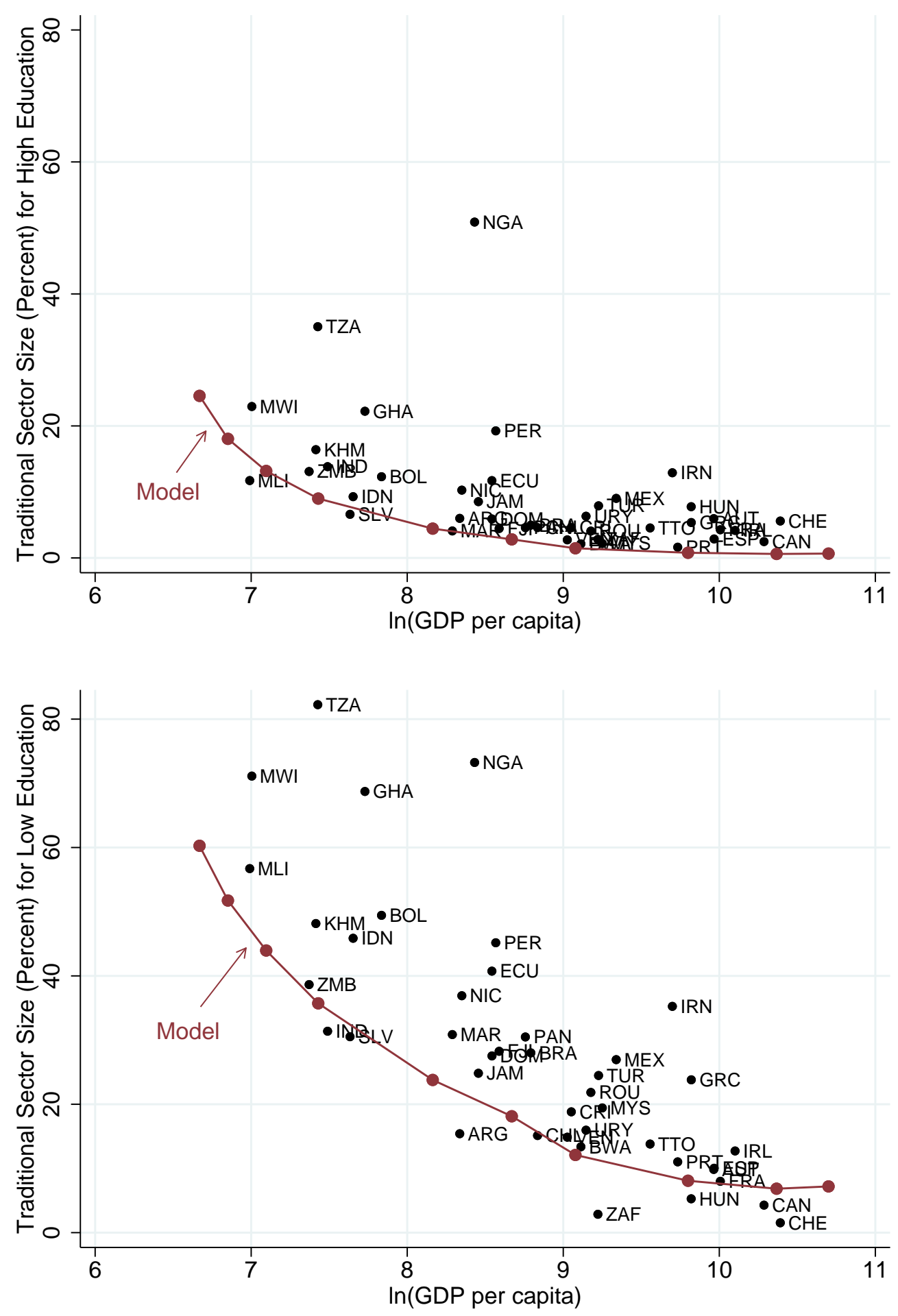

Note: This figure plots the size of the traditional sector against log GDP per capita in the data and model. The top panel is for high-educated workers, and the bottom is for low-educated workers. 
Figure 7: Unemployment Rates in the Model and Data

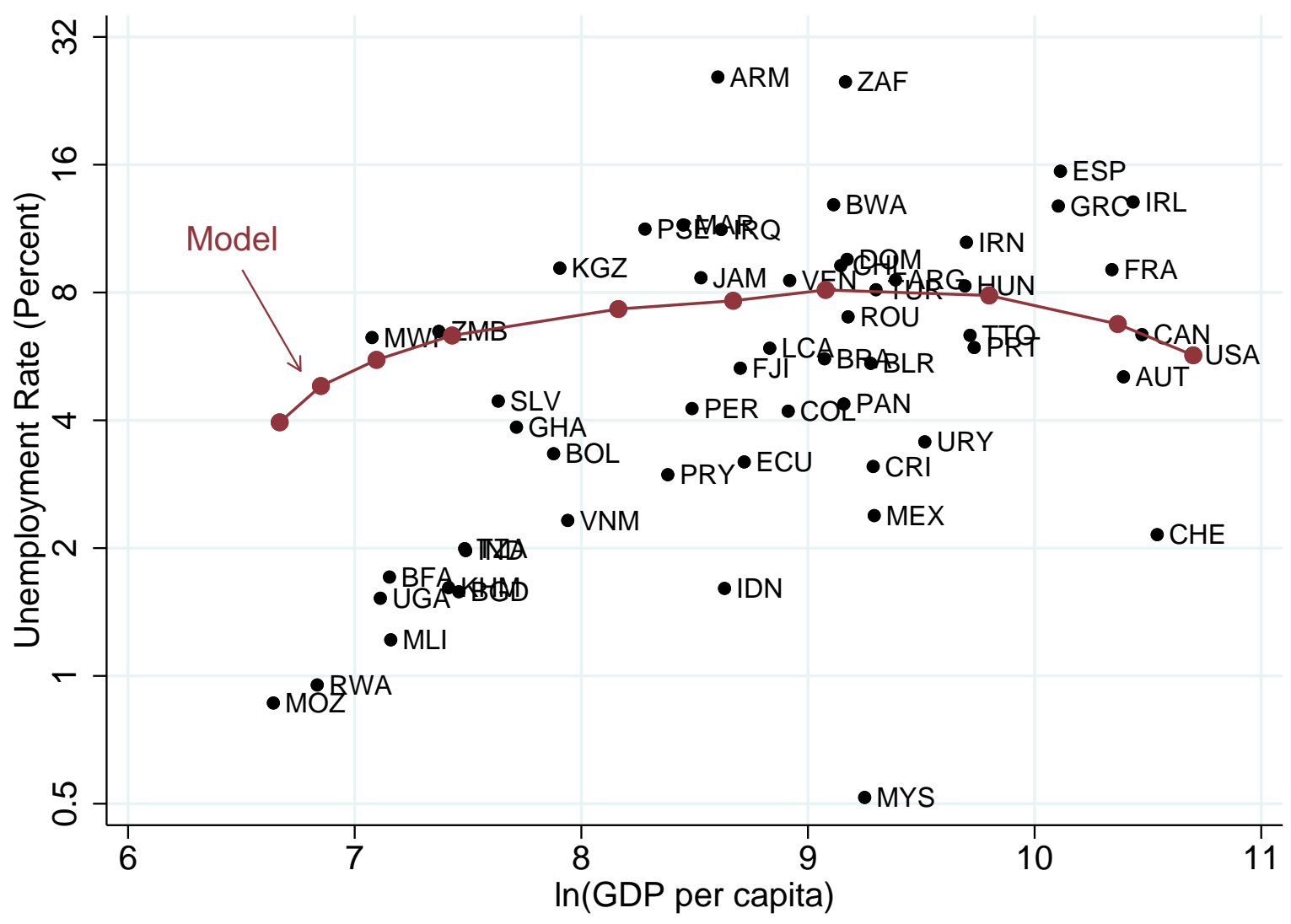

Note: This figure plots the aggregate unemployment rate against log GDP per capita. Each dot represents one country in our data, and the solid line is the prediction of the quantitative model.

in the data. For the aggregate unemployment rate, the model yields a semi-elasticity of 0.5 compared to 1.8 in the data. Thus, the model accounts for around 30 percent $(0.5 / 1.8)$ of the empirical relationship between unemployment and log GDP per capita. Unemployment rates for the low-educated have a semi-elasticity of 1.7 in the model, compared to 3.2 in the data. The high-educated semi-elasticities are fairly similar, at 0.4 in the model and 0.5 in the data. The ratio of low- to high-educated unemployment rates is 0.5 in the data and 0.3 in the model. Largely consistent with the above discussions, the model yields magnitudes similar to the data but underpredicts the empirical elasticities. Traditional-sector slopes are similar in the model and data, at -15.9 in the model and -13.4 in the data.

We also calibrated our model using an alternative strategy to discipline the elasticity of technological change in the traditional sector with respect to technological change in the modern sector. We targeted the slope of the aggregate traditional sector share on log GDP per capita instead of the elasticity of the relative price of traditional sector output with respect to GDP per capita. This yields $\theta_{1}=0.19$ when we match the traditional sector 
Figure 8: Unemployment Ratio in the Model and Data

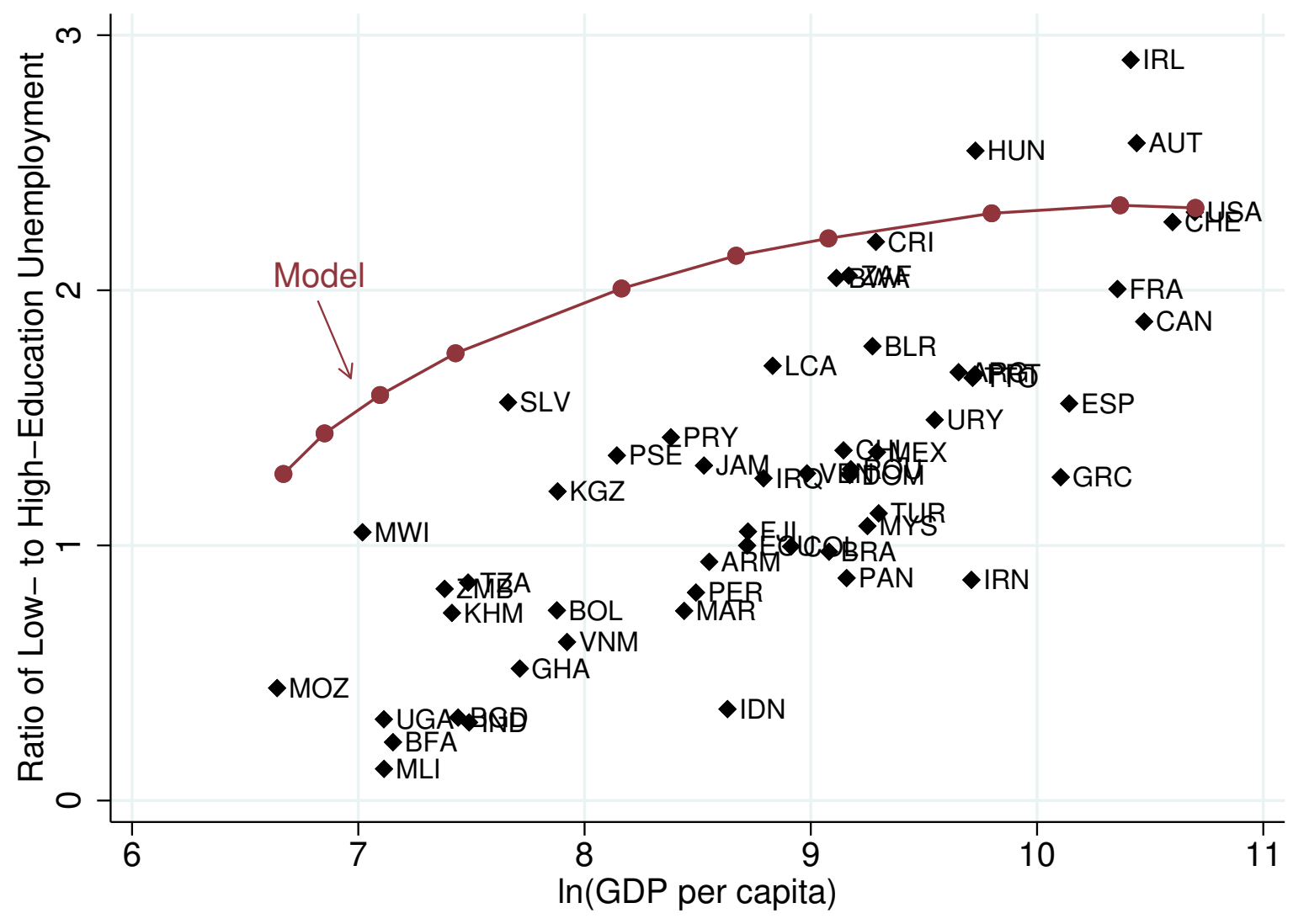

Note: This figure plots the ratio of unemployment for the low-educated to unemployment for the high-educated. Each dot represents one country in our database. The solid line is the prediction of the quantitative model.

share slope of -15.9 precisely. When calibrated this way, the model yields a slightly higher relative price elasticity of 0.67 , which is still in the range of the empirical estimates 0.4 to 0.7 . Using this strategy, the model accounts for more than 40 percent $(0.75 / 1.8)$ of the empirical relationship between unemployment and log GDP per capita. It yields the same slope of 0.3 for the ratio of low- to high-educated unemployment as in the benchmark. Appendix Table $\mathrm{C} 2$ reports all the model slopes when using the alternative calibration strategy.

In our benchmark model, the unemployment benefits replacement rate $b$ is set to 0.45 in all economies. But in reality, the benefits replacement rate is higher in richer countries. To study the quantitative impact of varying $b$ values, we now calibrate the model using increasing $b$ values from 0 in the poorest country to 45 percent in the United States.

Panel A of Table 8 reports the slope coefficients from regressions of the unemployment rate and unemployment ratio on log GDP per capita and a constant, in our benchmark model and 
Table 7: Slope Coefficients in Data and Quantitative Model

\begin{tabular}{lcc}
\hline \hline & Data & Model \\
\hline Aggregate traditional sector share & -15.9 & -13.4 \\
Traditional-sector share for low educated & -16.7 & -12.7 \\
Traditional-sector share for high educated & -4.9 & -5.0 \\
Aggregate unemployment rate & 1.8 & 0.5 \\
Unemployment rate for low-educated & 3.2 & 1.7 \\
Unemployment rate for high-educated & 0.5 & 0.4 \\
Ratio of unemployment rates $u_{l} / u_{h}$ & 0.5 & 0.3 \\
Relative price $P_{T}$ & 0.6 & 0.60 \\
\hline \hline
\end{tabular}

Note: The table reports estimated slope coefficients from regressions of the statistics in each row on log GDP per capita. The first data column reports the slopes from our cross-country database, and the second data column reports the slopes from the quantitative model.

in the model with varying $b$ values. The model with varying $b$ values predicts an aggregate unemployment rate elasticity of 0.72 , compared to 0.52 in the benchmark model. This accounts for 41 percent of the empirical relationship in the data, which is 11 percentage points higher than in our benchmark model. For the unemployment ratio, the model with varying $b$ values has an elasticity of 0.26 , very similar to 0.25 in the benchmark model. In addition, Panel B of Table 8 reports the difference of average unemployment rates and ratios for the top and bottom income countries, both in the data and in two versions of the model. The top income quartile countries in our sample have an average unemployment rate of 8.0 percent compared to 2.7 percent for the bottom quartile countries. The difference is 5.3 percentage points. The model with varying $b$ values can account for 52 percent of this unemployment rate difference, compared to 42 percent for the benchmark model. For the unemployment ratio difference, the two versions of model have similar explanatory power, 51 percent for the benchmark model and 54 percent for the model with increasing $b$ values.

In summary, an alternative model which includes increasing unemployment benefits with development helps to explain the increase in the unemployment rate with GDP per capita, but not the increase in the unemployment ratio. Thus, although the quantitive model explains a substantial portion of the aggregate unemployment patterns in question, and the higher unemployment benefits in richer countries increase the model's explanatory power, much of the data are left unexplained by the model. Additional forces that help to explain the cross-country relationship between average unemployment and income per capita are a subject for future research. 
Table 8: Benchmark Model and Model with Varying $b$

\begin{tabular}{lccccc}
\hline \hline & \multicolumn{5}{c}{ Panel A: Slope Coefficients } \\
& Data & Benchmark & Explained & Varying $b$ & Explained \\
\hline Unemployment & 1.76 & 0.52 & $30 \%$ & 0.72 & $41 \%$ \\
$u_{L} / u_{H}$ & 0.47 & 0.25 & $53 \%$ & 0.26 & $55 \%$ \\
\hline
\end{tabular}

Panel B: Top Quartile Minus Bottom Quartile

\begin{tabular}{lccccc} 
benchmark & Data & Benchmark & Explained & Varying $b$ & Explained \\
\hline Unemployment & 5.3 & 2.2 & $42 \%$ & 2.78 & $52 \%$ \\
$u_{L} / u_{H}$ & 1.3 & 0.7 & $51 \%$ & 0.69 & $54 \%$ \\
\hline \hline
\end{tabular}

Note: Panel A reports the slope coefficients from regressions of the unemployment rate and unemployment ratio on log GDP per capita and a constant. Panel B reports the difference between the top and bottom quartiles of the world income distribution. The first data column reports the values from our cross-country database. The second and third data columns report the values from the benchmark model and the percent of the data explained. The fourth and fifth columns report the values from the alternative model, with varying $b$, and the percent explained from that model.

\subsection{Sensitivity Analysis}

As noted above, the literature provides us with a range of plausible elasticities of substitution rather than a single firm value. In this section, we explore the sensitivity of our model's predictions to the value for the elasticity of substitution. We compute the model's predictions for elasticities 2.5 and 3.5, in particular, in addition to the benchmark value of 3.

We present the results in Table 9. Each row reports the slope coefficient from a regression of the variable on question on log GDP per capita. The first column is the data slope coefficients, the second is that of the benchmark model, and the third and fourth columns are the slope coefficients in the model with the lower and higher values of the substitution elasticities, respectively. For the lower value of 2.5, the model underpredicts the slope of the traditional sector shares on log GDP per capita. As a result, the aggregate unemployment rate varies less with GDP per capita (0.1 versus 0.5 in the benchmark model), as do unemployment rates for low-educated workers (1.2 versus 1.7 in the benchmark) and high-educated workers ( 0.2 versus 0.4 in the benchmark). The ratio of low-to-high unemployment rates also varies less with GDP per capita than in the benchmark (0.17 versus 0.25$)$. The relative price varies more than in the benchmark (0.64 versus 0.60$)$. 
Table 9: Sensitivity Analysis of Model Elasticity of Substitution, $\frac{1}{1-\sigma}$

\begin{tabular}{|c|c|c|c|c|}
\hline & Data & Benchmark & $\frac{1}{1-\sigma}=2.5$ & $\frac{1}{1-\sigma}=3.5$ \\
\hline Aggregate traditional sector share & -15.9 & -13.4 & -9.2 & -17.1 \\
\hline Traditional-sector share for low educated & -16.7 & -12.7 & -8.4 & -16.4 \\
\hline Traditional-sector share for high educated & -4.9 & -5.0 & -2.6 & -7.8 \\
\hline Aggregate unemployment rate & 1.8 & 0.5 & 0.1 & 0.9 \\
\hline Unemployment rate for low-educated & 3.2 & 1.7 & 1.2 & 2.1 \\
\hline Unemployment rate for high-educated & 0.5 & 0.4 & 0.2 & 0.5 \\
\hline Ratio of unemployment rates $u_{l} / u_{h}$ & 0.5 & 0.25 & 0.17 & 0.32 \\
\hline Relative price $P_{T}$ & 0.6 & 0.60 & 0.64 & 0.56 \\
\hline
\end{tabular}

Note: This table reports the slope coefficients from regressions of the statistics in each row on log GDP per capita and a constant. The first column is for an elasticity of substitution between modern and traditional output of 2.5, the second column is the benchmark model, and the third column is for an elasticity of substitution of 3.5 .

For the higher value of 3.5, the model over-predicts the slope of the traditional sector share on log GDP per capita. The unemployment rate varies substantially more with GDP per capita than in the benchmark, both in the aggregate and by education level. The unemployment ratio has a slope of 0.32 compared to 0.25 in the benchmark, and is somewhat closer to the slope of 0.5 in the data.

The intuition for these results is as follows. The change in the level of unemployment is driven by the exodus from the traditional sector, which, in turn, is driven by the increase in the ratio of marginal value products of labor: $\frac{A_{M}}{P_{T} A_{T}}$. The smaller is the elasticity of substitution, the less this ratio changes because the rise in $P_{T}$ offsets the rise in $A_{M}$ as we move from the poorest to the richest country. In the benchmark model, the slope of this ratio on log GDP per capita is 0.87 , only 0.79 when the elasticity is 2.5 , and 0.95 when the elasticity is 3.5 . That is why the model predicts so much more change in unemployment when the elasticity is 3.5 than when it is 2.5 .

We conclude that the model is sensitive to values of the elasticity of substitution between modern- and traditional-sector output. For our benchmark value of 3 the model explains the traditional-sector employment share across countries quite well, suggesting that this may be a sensible value ex-post. For all three of the values chosen, the model underpredicts the slope of the relationship between unemployment and GDP per capita. 


\section{Historical Evidence}

In this section, we report historical evidence from countries that have high income per capita today to explore how their average unemployment rates have evolved over the long run with income levels. We first look at aggregate unemployment rates from Australia, France, Germany, the United Kingdom and the United States in the period before World War I compared to the most recent evidence. We then look at more disaggregate evidence from the United States.

\subsection{Historical Unemployment Rates}

The earliest evidence on unemployment that we can find comes from the late 19th century or early 20th century. For simplicity, we consider two periods: an early period containing all data pre-World War I, and a recent period comprised of the most recently available data covering the same number of years. There are five countries for which we found aggregate unemployment data for at least ten years before WWI started in 1914: Australia, France, Germany, the United Kingdom and the United States. The recent period is then defined as 2004 - 2016 for Australia, 1998 - 2016 for France, 1990 - 2016 for Germany, 1984 - 2016 for the UK, and 1972 - 2016 for the U.S. The recent aggregate unemployment rate data are combined from the World Bank, the U.K. office for National Statistics, and the U.S. BLS.

Table 10 reports the average unemployment rates in the early and recent periods for these five countries, the difference between the recent and early periods, and a permutation test of the difference between the recent and early periods. The recent unemployment rate is larger than the early period for all five countries. Among them, Australia's unemployment rate is very similar in the two periods, and the difference is statistically insignificant. For the remaining four, average unemployment is economically and statistically significantly higher in the recent period. France's unemployment is the highest overall in both periods, and rises from 7.4 to 8.9 percent. Germany's unemployment rises from 2.4 to 7.6 percent. The United Kingdom rises from 4.7 to 7.3 percent, and the United States rises from 5.1 to 6.4 percent. All of these countries had very large increases in GDP per capita over this period. We conclude that the historical evidence is consistent with our cross sectional finding that the aggregate unemployment rate increases when GDP per capita increases.

\subsection{Disaggregated U.S. Time Series Evidence}

We now turn to evidence from the U.S. time series micro data. These data allow us to go beneath the aggregate unemployment rates and to study what happens to unemployment and 
Table 10: Historical Unemployment Rates

\begin{tabular}{|c|c|c|c|c|}
\hline Country & $\begin{array}{l}\text { Early Period } \\
\text { (source) }\end{array}$ & $\begin{array}{l}\text { Uneml } \\
\text { Early }\end{array}$ & $\begin{array}{l}\text { loyment } \\
\text { Recent }\end{array}$ & $\begin{array}{c}\text { Difference } \\
\text { (p-value) }\end{array}$ \\
\hline Australia & $\begin{array}{l}1901-1913 \\
\text { (Mitchell 1992) }\end{array}$ & 5.17 & 5.26 & $\begin{array}{r}0.09 \\
(.48)\end{array}$ \\
\hline France & $\begin{array}{l}1895-1913 \\
\text { (Mitchell 1992) }\end{array}$ & 7.35 & 8.91 & $\begin{array}{c}1.55^{* * *} \\
(.00)\end{array}$ \\
\hline Germany & $\begin{array}{l}1887-1913 \\
\text { (Mitchell 1992) }\end{array}$ & 2.37 & 7.55 & $\begin{array}{c}5.18^{* * *} \\
(.00)\end{array}$ \\
\hline United Kingdom & $\begin{array}{c}1881-1913 \\
\text { (UK Central Statistical Office) }\end{array}$ & 4.71 & 7.29 & $\begin{array}{l}2.57^{* * *} \\
(.00)\end{array}$ \\
\hline United States & $\begin{array}{c}1869-1913 \\
\text { (Vernon 1994, Mitchell 1992) }\end{array}$ & 5.11 & 6.38 & $\begin{array}{l}1.27^{* * *} \\
(.00)\end{array}$ \\
\hline
\end{tabular}

Note: The table reports the average unemployment rates in the early and recent periods, and the results of a one-sided permutation test of whether the recent period has a larger unemployment rate. The early period is defined as the years before WWI; and the recent period is defined as a corresponding year to 2016 such that we have the same number of years for the two periods in each country; see the text for exact dates.

traditional sector employment by education group. The data allow us to test our theory's prediction that unemployment rates rose, particularly for the low-educated. ${ }^{15}$

To do so, we draw on the U.S. census every decade from 1910 to 2010 from IPUMS International (Minnesota Population Center, 2017). To maintain consistency across years, we restrict attention to workers aged 16 and over in all states except Alaska and Hawaii. The first row of Table 11 reports the slope coefficients from regressions of the unemployment rates on $\log$ GDP per capita and a constant. As the table shows, unemployment rates rose with log GDP per capita on average, particularly for the less-educated. The estimated slope of the ratio of low-educated unemployment to high-educated unemployment is 0.7 using these data, compared with 0.5 in the cross-country data. We conclude that disaggregated unemployment rates from historical U.S. data are largely consistent with our theory and our cross-country evidence.

Our theory also predicts that the size of the traditional sector has fallen over time in the United States. To test this prediction, we use the census data from 1960 to 2010 to measure the size of the traditional sector according to our proxy of self-employed workers in low-skilled occupations. The second row of Table 11 reports the slope coefficient from a regression of

\footnotetext{
${ }^{15}$ Strictly speaking, our theory applies to comparisons across steady states, so the predictions in this section are suggested by our theory rather than directly derived from it.
} 
Table 11: Slope Coefficients for U.S. Time Series

\begin{tabular}{lc|ccc}
\hline & & \multicolumn{3}{|c}{ Worker Education Group } \\
& All Workers & Low & High & Ratio \\
\hline Unemployment rate & $3.3^{* *}$ & $10.6^{* * *}$ & $3.8^{* *}$ & $.7^{* *}$ \\
& $(1.6)$ & $(2.3)$ & $(1.6)$ & $(.3)$ \\
Traditional sector share & $-2.6^{* *}$ & -1.6 & -.4 & \\
& $(1.0)$ & $(1.3)$ & $(.7)$ & \\
\hline \hline
\end{tabular}

Note: The table reports the slope coefficients from regressions of unemployment rates and the traditional sector share on log GDP per capita and a constant. ${ }^{* *}, * *$ and $*$ indicate statistical significance at the 1-percent, 5-percent and 10-percent levels.

the traditional sector share on log GDP per capita and a constant. As the theory predicts, the traditional-sector share decreases significantly with log GDP per capita, mostly driven by the decrease for the low-education group. We conclude that our theory performs adequately here as well.

\section{Conclusions}

We draw on household survey evidence from around the world to document that unemployment rates are higher, on average, in rich countries than in poor countries. The pattern is particularly pronounced for the less-educated, whose unemployment rates are strongly increasing in GDP per capita, whereas unemployment for the more-educated is roughly constant on average across countries. Our findings imply that the low-educated are more likely to be unemployed than the high-educated in rich countries, whereas the opposite is true in poor countries.

To explain these facts, we build a two-sector model that combines labor search, as in Diamond (1982) and Mortensen and Pissarides (1994), with a traditional self-employment sector, as in Parente, Rogerson, and Wright (2000). In our model, countries differ exogenously in the productivity of the modern sector, in which worker productivity depends on ability, and workers offer their services in a labor market with search frictions. All countries have access to an identical traditional sector governed by self-employment and production in which ability plays no role. As such, our model features skill-biased technology differences across countries, as emphasized by, for example, Caselli and Coleman (2006). Workers are heterogeneous and sort as in Roy (1951). As productivity of the modern sector rises, progressively more workers sort into the modern sector. Unemployment levels rise, and particularly so for the less able, 
as proxied by low education in our empirical findings. A quantitative analysis of the model shows that the model explains a reasonable fraction - on the order of one third - of the cross-country facts that we document.

Our model suggests that at least some rise in unemployment is a natural consequence of the development process, as skilled workers search for jobs, rather than a sign of worsening economic opportunities as countries grow. At the same time, by making unemployment more predictable, we take the first steps toward providing a benchmark against which policy makers can judge the efficiency of their labor markets.

\section{References}

Adamopoulos, T., and D. Restuccia (2014): "The Size Distribution of Farms and International Productivity Differences," American Economic Review, 104(6), 1667-97.

Aguiar, M., and E. Hurst (2007a): "Lifecycle Prices and Production," American Economic Review, 97(5), 1533-59.

(2007b): "Measuring Trends in Leisure: The Allocation of Time Over Five Decades," Quarterly Journal of Economics, 122(3), 969-1006.

Akcigit, U., H. Alp, And M. Peters (2018): "Lack of Selection and Limits to Delegation: Firm Dynamics in Developing Countries," Unpublished Working Paper, Yale University.

Aruoba, S. B., M. A. Davis, and R. Wright (2016): "Homework in Monetary Economics: Inflation, Home Production, and the Production of Homes," Review of Economic Dynamics, 21, 105-124.

Autor, D. (2002): "Skill Biased Technical Change and Rising Inequality: What is the Evidence? What are the Alternatives?," Unpublished Working Paper, MIT.

Banerjee, A., P. Basu, And E. Keller (2016): "Cross-Country Disparities in Skill Premium and Skill Acquisition," Unpublished Working Paper, Durham University.

Banerjee, A. V., And A. F. Newman (1993): "Occupational Choice and the Process of Development," Journal of Political Economy, 101(2), 274-98.

Baxter, M., and U. J. Jermann (1999): "Household Production and the Excess Sensitivity of Consumption to Current Income," American Economic Review, 84(4), 902-920.

Benhabib, J., R. Rogerson, and R. Wright (1991): "Homework in Macroeconomics: Household Production and Aggregate Fluctuations," Journal of Political Economy, 99(6), 1166-1187. 
Bick, A., N. Fuchs-Schuendeln, and D. Lagakos (2018): "How Do Hours Worked Vary with Income? Cross-Country Evidence and Implications," American Economic Review, 108(8), 170-99.

Blanchard, O. J., and L. H. Summers (1986): "Hysteresis and the European Unemployment Problem," NBER Macroeconomics Annual, 1.

Boppart, T. (2014): "Structural Change and the Kaldor Facts in a Growth Model With Relative Price Effects and Non?Gorman Preferences," Econometrica, 82(6), 2167-2196.

Braxton, J. C., K. Herkenhoff, and G. Phillips (2018): "Can the Unemployed Borrow? Implications for Public Insurance," Unpublished Manuscript, University of Minnesota.

Bridgman, B., G. Duernecker, and B. Herrendorf (2018): "Structural Transformation, Marketization, and Household Production around the World," Journal of Development Economics, 133, 102-126.

Broda, C., And D. E. Weinstein (2006): "Globalization and the Gains from Variety," Quarterly Journal of Economics, 121(2), 541-585.

Buera, F. J., and J. P. Kaboski (2012): "The Rise of the Service Economy," American Economic Review, 102, 2450-69.

Buera, F. J., J. P. Kaboski, And R. Rogerson (2015): "Skill-Biased Structural Change," Unpublished Working Paper, University of Notre Dame.

Buera, F. J., J. P. Kaboski, And Y. Shin (2011): "Finance and Development: A Tale of Two Sectors," American Economic Review, 101(8), 1964-2002.

Caselli, F. (2005): "Accounting for Cross-Country Income Differences," in Handbook of Economic Growth, ed. by P. Aghion, and S. N. Durlauf.

Caselli, F., and W. Coleman (2006): "The World Technology Frontier," American Economic Review, 96(3), 499-522.

Cavalcanti, P. F., A. Monge-Naranjo, and L. Torres de Mello (2016): "Of Cities and Slums," Federal Reserve Bank of St. Louis Working Paper 2016-022A.

Chang, Y., And F. Schorfheide (2003): "Labor-Supply Shifts and Economic Fluctuations," Journal of Monetary Economics, 50, 1751-1768.

Chodorow-Reich, G., and L. Karabarbounis (2016): "The Cyclicality of the Opportunity Cost of Employment," Journal of Political Economy, 124(6), 1563-1618. 
Cole, H. L., J. Greenwood, and J. Sanchez (2016): "Why Doesn't Technology Flow from Rich to Poor Countries?," Journal of Political Economy, 84(4), 1477-1521.

Diamond, P. A. (1982): “Aggregate Demand Management in Search Equilibrium," Journal of Political Economy, 90(8), 881-894.

Donovan, K., J. Lu, And T. Schoellman (2018): "Labor Market Flows and Development," Unpublished Manuscript, University of Notre Dame.

Duarte, M., and D. Restuccia (2010): "The Role of the Structural Transformation in Aggregate Productivity," Quarterly Journal of Economics, 125(1), 129-173.

Feenstra, R. C., R. InklaAr, and M. P. Timmer (2015): "The Next Generation of the Penn World Table," American Economic Review, 105(10), 3150-3182.

Feng, Y., And L. Rickey (2016): "Development and Selection into Necessity versus Opportunity Entrepreneurship," Unpublished Working Paper, UCSD.

Fields, G. S. (1980): "Education and Income Distribution in Developing Countries: A Review of the Literature," World Bank Staff Working Paper No. 402 (pp. 231 - 315).

- (2004): "A Guide to Multi-sector Labor Market Models," Unpublished Working Paper, Cornell University.

Fujita, S., And G. Ramey (2012): "Exogenous Versus Endogenous Separation," American Economic Journal: Macroeconomics, 4(4), 68-93.

Gollin, D. (2008): “Nobody's Business But My Own: Self-Employment and Small Enterprise in Economic Development," Journal of Monetary Economics, 55(2), 219-233.

Gollin, D., D. Lagakos, and M. E. Waugh (2014): "The Agricultural Productivity Gap," Quarterly Journal of Economics, 129(2), 939-993.

Gollin, D., S. L. Parente, and R. Rogerson (2004): "Farm Work, Home Work and International Productivity Differences," Review of Economic Dynamics, 7, 827-850.

Greenwood, J., And Z. Hercowitz (1991): "The Allocation of Capital and Time Over the Business Cycle," Journal of Political Economy, 99(6), 1188-1214.

Greenwood, J., J. M. Sanchez, and C. Wang (2010): "Financing Development: The Role of Information Costs," American Economic Review, 100(4), $1875 ? 1891$.

Hall, R. E., And A. I. Mueller (Forthcoming): "Wage Dispersion and Search Behavior: The Importance of Non-Wage Job Values," Journal of Political Economy. 
Harris, J. R., and M. P. Todaro (1970): "Migration, Unemployment and Development: A Two-Sector Analysis," American Economic Review, 60(1), 126-142.

Herrendorf, B., R. Rogerson, and A. Valentinyi (2014): "Growth and Structural Transformation," in Handbook of Economic Growth, ed. by P. Aghion, and S. N. Durlauf, vol. 2, chap. 6, pp. 855-941. Elsevier.

HJort, J., And J. Poulsen (forthcoming): "The Arrival of Fast Internet and Employment in Africa," American Economic Review.

Hsieh, C.-T., and P. J. Klenow (2007): "Relative Prices and Relative Prosperity," American Economic Review, 97(3), 562-585.

Jerzmanowski, M., and R. Tamura (2017): "Directed Technological Change and Cross Country Income Differences: A Quantitative Analysis," Unpublished Working Paper, Clemson University.

Karabarbounis, L. (2014): "Production, Labor Wedges, and International Business Cycles," Journal of Monetary Economics, 64, 68-84.

Krueger, A. B., And A. Mueller (2010): "Job Search and Unemployment Insurance: New Evidence from Time Use Data," Journal of Public Economics, 94(3), 298 - 307.

La Porta, R., And A. Shleifer (2008): "The Unofficial Economy and Economic Development," Brookings Papers on Economic Activity, 2, 275-363.

(2014): "Informality and Development," Journal of Economic Perspectives, 28(3), $109-26$.

Lagakos, D., And M. E. Waugh (2013): "Selection, Agriculture, and Cross-Country Productivity Differences," The American Economic Review, 103(2), 948-980.

Lepper, F. (2004): "Comparable Annual Employment and Unemployment Estimates," Discussion paper, Department of Statistics, International Labour Office, Geneva.

LEwis, W. A. (1954): "Economic Development with Unlimited Supplies of Labor," The Manchester School, 22(2), 139-91.

LJungqvist, L., And T. J. SArgent (2008): "Two Questions about European Unemployment," Econometrica, 76(1), 1-29.

Malmberg, H. (2016): "Human Capital and Development Accounting Revisted," Unpublished Working Paper, IIES Stockholm.

McGrattan, E. R., R. Rogerson, and R. Wright (1997): "An Equilibrium Model of 
the Business Cycle with Household Production and Fiscal Policy," International Economic Review, 38, 267-290.

McKiernan, K. (2018): "Welfare Impacts of Social Security Reform: The Case of Chile in 1981," Unpublished Working Paper, Vanderbilt University.

Mestieri, M., D. Comin, and D. Lashkari (2018): "Structural Change with Long-run Income and Price Effects," Unpublished Working Paper, Northwestern University.

Mincer, J. (1991): "Education and Unemployment," NBER Working Paper No. 3838.

Minnesota Population Center (2017): "Integrated Public Use Microdata Series, International: Version 6.5 [dataset]," Minneapolis: University of Minnesota, http://doi.org/10.18128/D020.V6.5.

Mortensen, D., and C. Pissarides (1994): "Job Creation and Job Destruction in the Theory of Unemployment," Review of Economic Studies, 61, 397-415.

Mueller, A. I. (2017): "Separations, Sorting, and Cyclical Unemployment," American Economic Review, 107(7), 2081-2107.

Ngai, R. L., and C. A. Pissarides (2008): "Trends in Hours and Economic Growth," Review of Economic Dynamics, 11(2), 239-56.

(2011): "Taxes, Social Subsidies and the Allocation of Work Time," American Economic Journal: Macroeconomics, 3(4), 1-26.

Nickell, S., L. Nunziata, and W. Ochel (2004): "Unemployment in the OECD Since the 1960s. What Do We Know?," Economic Journal, 115(500), 1-27.

Parente, S. L., R. Rogerson, and R. Wright (2000): "Homework in Development Economics: Household Production and the Wealth of Nations," Journal of Political Economy, 108(4), 680-687.

Porzio, T., And G. Santangelo (2017): "Structural Change and the Supply of Agricultural Workers," Unpublished Working Paper, University of California San Diego.

Poschke, M. (2018): "Wage Employment, Unemployment and Self-Employment Across Countries," Unpublished Manuscript, McGill University.

Ramey, V. A., And N. Francis (2009): "A Century of Work and Leisure," American Economic Journal: Macroeconomics, 1(2), 189-224.

RAUCH, J. E. (1991): "Modelling the Informal Sector Informally," Journal of Development Economics, 35(1), 33-47. 
Restuccia, D., and C. Urrutia (2001): "Relative Prices and Investment Rates," Journal of Monetary Economics, 47(1), 93-121.

Rogerson, R. (2008): "Structural Transformation and the Deterioration of European Labor Market Outcomes," Journal of Political Economy, 116(2), 235-259.

Roy, A. (1951): "Some Thoughts on the Distribution of Earnings," Oxford Economic Papers, $3,135-46$.

Rupert, P., R. Rogerson, and R. Wright (1995): "Estimating Substitution Elasticities in Household Production Models," Economic Theory, 6, 179-93.

SchoAr, A. (2010): "The Divide between Subsistence and Transformational Entrepreneurship," in Innovation Policy and the Economy, ed. by J. Lerner, and S. Stern, chap. 3, pp. 57-81. University of Chicago Press.

Shimer, R. (2005): "The Cyclical Behavior of Equilibrium Unemployment and Vacancies," American Economic Review, 95(1).

Squire, L. (1981): Employment Policy in Developing Countries: A Survey of Issues and Evidence. New York: Published for the World Bank by Oxford University Press.

Turnham, D. (1993): Employment and Development: A New Review of Evidence. Paris, OECD.

United Nations (2008): "System of National Accounts, 2008," https://unstats.un.org/unsd/sna1993/WC-SNAvolume2.pdf.

U.S. Bureau of Labor Statistics (2016): Handbook of Methods. U.S. Government Printing Office, Washington, D.C.

Wolcotт, E. (2018): "Employment Inequality: Why Do the Low-Skilled Work Less Now?," Unpublished Working Paper, Middlebury College.

Young, A. (2013): "Inequality, the Urban-Rural Gap and Migration," The Quarterly Journal of Economics, 129(2), 939-993. 


\section{Appendices}

\section{A Data Appendix}

Among the 199 surveys listed below, there are 11 from earlier than 1990, 59 from the 1990s, 88 from the 2000s, and 41 from 2010 and later. Among the 84 countries, there are 55 for which we have at least two surveys.

Table A.1: Tier 1: Most Comparable Surveys

Tier 1a: Searched for work last week

\begin{tabular}{|c|c|c|}
\hline Country & Year & Source \\
\hline Azerbaijan & 1995 & Survey of Living Conditions \\
\hline Bangladesh & $2000,2005,2010$ & Household Income-Expenditure Survey (HIES) \\
\hline Bolivia & 1992, 2001 & IPUMS-I \\
\hline Botswana & 2001,2011 & IPUMS-I \\
\hline Brazil & 2010 & IPUMS-I \\
\hline Burkina Faso & 2014 & LSMS \\
\hline Burkina Faso & 2006 & IPUMS-I \\
\hline Canada & 2011 & IPUMS-I \\
\hline Chile & 1992, 2002 & IPUMS-I \\
\hline Colombia & 1993,2005 & IPUMS-I \\
\hline Costa Rica & 2000,2011 & IPUMS-I \\
\hline Cuba & 2002 & IPUMS-I \\
\hline Dominican Republic & 2002 & IPUMS-I \\
\hline Ecuador & 1990, 2001, 2010 & IPUMS-I \\
\hline El Salvador & 1992 & IPUMS-I \\
\hline Fiji & 2007 & IPUMS-I \\
\hline Ghana & 1984,2000 & IPUMS-I \\
\hline Ghana & 1998 & Living Standards Survey \\
\hline Greece & 1996, 2001, 2011 & IPUMS-I \\
\hline Hungary & 2011 & IPUMS-I \\
\hline India & 1983, 1987, 1993, 1999, 2004 & IPUMS-I \\
\hline Indonesia & 1990, 1995, 2010 & IPUMS-I \\
\hline Indonesia & 2014 & Indonesia Family Life Survey \\
\hline Ireland & 2011 & IPUMS-I \\
\hline Jamaica & 1991,2001 & IPUMS-I \\
\hline Kenya & 2009 & IPUMS-I \\
\hline
\end{tabular}




\begin{tabular}{|c|c|c|}
\hline Malaysia & 1991, 2000 & IPUMS-I \\
\hline Mexico & 1990, 1995, 2000, 2010, 2015 & IPUMS-I \\
\hline Mongolia & 2000 & IPUMS-I \\
\hline Mozambique & 1997,2007 & IPUMS-I \\
\hline Nigeria & 2010 & IPUMS-I \\
\hline Pakistan & 1973 & IPUMS-I \\
\hline Panama & $1990,2000,2010$ & IPUMS-I \\
\hline Paraguay & 1992 & IPUMS-I \\
\hline Peru & 2007 & IPUMS-I \\
\hline Peru & 1994 & Living Standards Survey \\
\hline Philippines & 1990 & IPUMS-I \\
\hline Poland & 2002 & IPUMS-I \\
\hline Portugal & 1991,2001 & IPUMS-I \\
\hline Romania & 1992, 2002, 2011 & IPUMS-I \\
\hline Rwanda & 2002 & IPUMS-I \\
\hline Saint Lucia & 1980, 1991 & IPUMS-I \\
\hline South Africa & 1993 & Integrated Household Survey \\
\hline South Sudan & 2008 & IPUMS-I \\
\hline Spain & 2011 & IPUMS-I \\
\hline Sudan & 2008 & IPUMS-I \\
\hline Tajikistan & 1999 & LSMS \\
\hline Tanzania & 2002,2012 & IPUMS-I \\
\hline Trinidad and Tobago & 1970, 1980, 1990, 2000, 2011 & IPUMS-I \\
\hline Uganda & 1991, 2002 & IPUMS-I \\
\hline United States & 1960 & IPUMS-I \\
\hline Venezuela & 2001 & IPUMS-I \\
\hline Zambia & 1990,2010 & IPUMS-I \\
\hline
\end{tabular}

Tier 1b: Searched for work in the last 4 weeks

\begin{tabular}{ccc}
\hline Argentina & 1991 & IPUMS-I \\
Armenia & 2011 & IPUMS-I \\
Belarus & 2009 & IPUMS-I \\
Brazil & 2000 & IPUMS-I \\
Canada & 1991,2001 & IPUMS-I \\
\hline Dominican Republic & 2010 & IPUMS-I \\
Italy & 2001 & IPUMS- I \\
Jordan & 2004 & IPUMS-I
\end{tabular}




\begin{tabular}{ccc} 
Panama & 2010 & IPUMS-I \\
Paraguay & 2002 & IPUMS-I \\
\hline South Africa & 2007,2011 & IPUMS-I \\
United States & $1970,1980,1990,2000,2005$ & IPUMS \\
United States & $2001-2014$ & American Community Survey (ACS) \\
Bosnia and Herzegovina & 2004 & Living in Bosnia and Herzegovina Survey \\
Brazil & 1997 & Survey of Living Conditions \\
\hline Bulgaria & 2007 & Multi-topic Household Survey \\
Iran & 2011 & IPUMS-I \\
Iraq & 2012 & Household Socio-economic Survey \\
Malawi & 2013 & Integrated Household Panel Survey \\
Serbia & 2007 & LSMS \\
\hline Uganda & 2011 & National Panel Survey \\
\hline \hline
\end{tabular}


Table A.2: Tier 2: Comparable Search Questions, Less Comparable Duration Questions

\begin{tabular}{|c|c|c|c|}
\hline Country & Year & Source & Seeking window \\
\hline Armenia & 2001 & IPUMS-I & Current \\
\hline Bangladesh & 1991, 2001 & IPUMS-I & 7 days, main activity \\
\hline Bangladesh & 2011 & IPUMS-I & Current status \\
\hline Brazil & 1980 & IPUMS-I & Current \\
\hline Burkina Faso & 1996 & IPUMS-I & At least 3 days in the last week \\
\hline Cambodia & 1998,2008 & IPUMS-I & 6 months \\
\hline Egypt & 2006 & IPUMS-I & current \\
\hline El Salvador & 2007 & IPUMS-I & Current/ last week \\
\hline France & 2006, 2011 & IPUMS-I & Current \\
\hline Haiti & 2003 & IPUMS-I & Last month \\
\hline Hungary & 1990 & IPUMS-I & Current \\
\hline Iran & 2006 & IPUMS-I & Past 30 days \\
\hline Iraq & 1997 & IPUMS-I & Current \\
\hline Ireland & $1991,1996,2002,2006$ & IPUMS-I & Current \\
\hline Kyrgyz Republic & 1999,2009 & IPUMS-I & Current \\
\hline Malawi & 2008 & IPUMS-I & Last year \\
\hline Mali & 1998,2009 & IPUMS-I & 4 weeks \\
\hline Morocco & 1994,2004 & IPUMS-I & Current \\
\hline Nicaragua & 2005 & IPUMS-I & 2 weeks \\
\hline Portugal & 2011 & IPUMS-I & Current \\
\hline Rwanda & 1991 & IPUMS-I & Most of the week \\
\hline Senegal & 2002 & IPUMS-I & Continuously for at least 3 months \\
\hline Sierra Leone & 2004 & IPUMS-I & 4 weeks \\
\hline South Africa & 1996 & IPUMS-I & Current \\
\hline Switzerland & 2000 & IPUMS-I & Current \\
\hline Turkey & 1990,2000 & IPUMS-I & Current \\
\hline Uruguay & 2006, 2011 & IPUMS-I & 4 weeks \\
\hline Venezuela & 1990 & IPUMS-I & Current \\
\hline Zambia & 2000 & IPUMS-I & Primary activity, 7 days \\
\hline
\end{tabular}


Table A.3: Tier 3: Least Comparable Search or Activity Questions

\begin{tabular}{|c|c|c|c|c|}
\hline Country & Year & Source & Activity & Search \\
\hline Argentina & 2001,2010 & IPUMS-I & Exclude: for self-consumption & 4 weeks \\
\hline Austria & 1991 & IPUMS-I & $\begin{array}{l}\text { A minimum average of } 12 \\
\text { hours per week }\end{array}$ & Current \\
\hline Austria & 2001 & IPUMS-I & 7 days & Only previously employed \\
\hline Austria & 2011 & IPUMS-I & No text & No text \\
\hline Belarus & 1999 & IPUMS-I & Exclude: for self-consumption & Yes \\
\hline Botswana & 2011 & IPUMS-I & 4 Weeks & \\
\hline Cameroon & 2005 & IPUMS-I & 7 Days & $\begin{array}{l}\text { Last } 7 \text { days for worked before; } \\
\text { now for looking for the first job }\end{array}$ \\
\hline China & 1990 & IPUMS-I & No text & No text \\
\hline Ethiopia & 2007 & IPUMS-I & Standard & No text \\
\hline France & 1990,1999 & IPUMS-I & Current & Enrollment ANPE \\
\hline Fiji & 1996 & IPUMS-I & Worked for money & Not comparable \\
\hline Ghana & 2010 & IPUMS-I & No text & No text \\
\hline Hungary & 2001 & IPUMS-I & Current & Unemployment benefit \\
\hline India & 2009 & IPUMS-I & Standard & Only 12 months main activity available \\
\hline Liberia & 2008 & IPUMS-I & 12 Months & 12 months \\
\hline Netherlands & 2001 & IPUMS-I & No Text & Not comparable \\
\hline Palestine & 1997,2007 & IPUMS-I & 7 Days & $\begin{array}{l}\text { Included did not seek but } \\
\text { want to work }\end{array}$ \\
\hline Peru & 1993 & IPUMS-I & Not comparable & Not comparable \\
\hline Portugal & 1981 & IPUMS-I & 7 Days & Text not available \\
\hline Slovenia & 2002 & IPUMS-I & Current & $\begin{array}{l}\text { Registered as unemployed at the } \\
\text { employment service of Slovenia }\end{array}$ \\
\hline
\end{tabular}




\begin{tabular}{cclcc}
\hline Spain & 1991,2001 & IPUMS-I & 7 Days & Unemployed, worked previously \\
South Africa & 2001 & IPUMS-I & 4 Weeks & Could not find work \\
Switzerland & 1990 & IPUMS-I & Principal occupation & Current \\
Ukraine & 2001 & IPUMS-I & Status & Unemployment allowances, unemployed \\
Vietnam & 2009,1991 & IPUMS-I & Earn income & 4 Weeks \\
\hline \hline
\end{tabular}




\section{B Model Derivation and Proofs}

\section{B.1 Model Derivations}

In this subsection, we develop the expressions for $U(x)$ and $w(x)$, and show the intermediate steps to develop Equation (9). We start by simplifying Equations (4) - (7) to

$$
\begin{aligned}
(1-\delta) U(x) & =A_{M} b x+\delta \eta \theta^{1-\alpha}[E(x)-U(x)] \\
(1-\delta) E(x) & =w(x)+\delta s[U(x)-E(x)] \\
J(x) & =\frac{A_{M} x-w(x)}{1-\delta(1-s)} \\
\left(1-G\left(x^{*}\right)\right) A_{M} c & =\delta \eta \theta^{-\alpha} \int_{x^{*}}^{\bar{x}} J(x) g(x) d x .
\end{aligned}
$$

The firm receives $(1-\beta) S(x)=(1-\beta)[E(x)-U(x)+J(x)]=J(x)$ when a vacancy is filled. Combining this division of surplus with equation (B.3) gives

$$
E(x)-U(x)=\frac{\beta}{1-\beta} \frac{A_{M} x-w(x)}{1-\delta(1-s)} .
$$

Substituting equation (B.5) into equation (B.1) yields

$$
U(x)=\frac{1}{1-\delta}\left(A_{M} b x+\delta \eta \theta^{1-\alpha} \frac{\beta}{1-\beta} \frac{A_{M} x-w(x)}{1-\delta(1-s)}\right) .
$$

We can then solve for $w(x)$ by combining equations (B.6) and (B.5) with equation (B.2):

$$
w(x)=\frac{A_{M} b x}{1+k(\theta)}+\frac{k(\theta)}{1+k(\theta)} A_{M} x, \text { with } k(\theta)=\frac{\beta\left(\delta \eta \theta^{1-\alpha}+1-\delta+\delta s\right)}{(1-\beta)(1-\delta+\delta s)} .
$$

Substituting this solution into equations (B.3) and (B.6) gives us, respectively,

$$
\begin{gathered}
J(x)=\frac{A_{M} x(1-b)(1-\beta)}{\beta \delta \eta \theta^{1-\alpha}+1-\delta+\delta s} \\
U(x)=\frac{1}{1-\delta}\left(A_{M} b x+\delta \eta \theta^{1-\alpha} \frac{\beta}{1-\beta} \frac{A_{M} x(1-b)(1-\beta)}{\beta \delta \eta \theta^{1-\alpha}+1-\delta+\delta s}\right) .
\end{gathered}
$$

Equation (B.8) appears as equation (8) in the text. Finally, substituting equation (B.7) into equation (B.4) and dividing both sides by $1-G\left(x^{*}\right)$ yields equation (9) that determines $\theta$ 
for any given level of $x^{*}$ :

$$
c=\frac{(1-\beta) \delta \eta \theta^{-\alpha}}{\beta \delta \eta \theta^{1-\alpha}+1-\delta+\delta s}(1-b) \mathbb{E}\left(x \mid x>x^{*}\right)
$$

\section{B.2 Proof of Proposition 1}

Equations (9) and (10) allow us to solve for unique values of $\theta$ and $x^{*}$. We first simplify equation (10) to

$$
\theta^{1-\alpha}=\frac{\left(A_{T}-A_{M} b x^{*}\right)(1-\delta+\delta s)}{\beta \delta \eta\left(A_{M} x^{*}-A_{T}\right)}
$$

Substitute this expression into equation (9), yielding a single equation that determines $x^{*}$ :

$$
\frac{\left(A_{T}-A_{M} b x^{*}\right)^{\frac{\alpha}{1-\alpha}} A_{M} x^{*}(1-b) c(1-\delta+\delta s)^{\frac{1}{1-\alpha}}}{\left(A_{M} x^{*}-A_{T}\right)^{\frac{1}{1-\alpha}}}=(1-\beta)(\delta \eta)^{\frac{1}{1-\alpha}} \beta^{\frac{\alpha}{1-\alpha}}(1-b) \mathbb{E}\left(x \mid x>x^{*}\right) .
$$

We assume that a solution $x^{*} \in(\underline{x}, \bar{x})$ to equation (B.10) exists. Since the existence of this solution implies that $A_{M} x^{*}-A_{T}>0$, it also implies the existence of a solution $\theta>0$. Moreover, if the solution $x^{*}$ is unique, then the solution $\theta$ is also unique.

To demonstrate uniqueness of the solution $x^{*}$, we first show that the left-hand side of equation (B.10) is decreasing in $x^{*}$. Inspection of equation (B.10) shows that a sufficient condition is that $A_{M} x^{*} /\left(A_{M} x^{*}-A_{T}\right)^{\frac{1}{1-\alpha}}$ is decreasing in $x^{*}$. We have

$$
\begin{aligned}
\operatorname{sign}\left[\frac{d \frac{A_{M} x^{*}}{\left(A_{M} x^{*}-A_{T}\right)^{\frac{1}{1-\alpha}}}}{d x^{*}}\right] & =\operatorname{sign}\left[\left(A_{M} x^{*}-A_{T}\right)^{\frac{1}{1-\alpha}}-\frac{x^{*}}{1-\alpha}\left(A_{M} x^{*}-A_{T}\right)^{\frac{\alpha}{1-\alpha}} A_{M}\right] \\
& =\operatorname{sign}\left[-A_{T}-\frac{\alpha A_{M} x^{*}}{1-\alpha}\right],
\end{aligned}
$$

which is negative. Since the right-hand side of equation (B.10) is increasing in $x^{*}$, then the $x^{*}$ that solves equation (B.10) must be unique.

Having demonstrated that the solution is unique, we turn to comparative statics of an increase in $A_{M}$. We want to show that the left-hand side of equation (B.10) is decreasing in $A_{M}$. It is 
sufficient to show:

$$
\begin{aligned}
\operatorname{sign}\left[\frac{d \frac{A_{M} x^{*}}{\left(A_{M} x^{*}-A_{T}\right)^{\frac{1}{1-\alpha}}}}{d A_{M}}\right] & =\operatorname{sign}\left[\left(A_{M} x^{*}-A_{T}\right)^{\frac{1}{1-\alpha}}-A_{M} \frac{1}{1-\alpha}\left(A_{M} x^{*}-A_{T}\right)^{\frac{\alpha}{1-\alpha}} x^{*}\right] \\
& =\operatorname{sign}\left[\left(A_{M} x^{*}-A_{T}\right)-\frac{A_{M} x^{*}}{1-\alpha}\right] \\
& =\operatorname{sign}\left[-A_{T}-\alpha \frac{A_{M} x^{*}}{1-\alpha}\right]
\end{aligned}
$$

Thus, we know that the sign of this derivative must be negative. We already know that the left- and right-hand sides of equation (B.10) are decreasing and increasing in $x^{*}$, respectively, so $d x^{*} / d A_{M}<0$ follows.

\section{B.3 Proof of Proposition 2}

It follows from Proposition 1 that $x^{*}$ decreases with $A_{M}$. As $x^{*}$ decreases, we see from equation (9) that $\theta$ decreases. Inspection of equation (11) then shows that $u$ must increase.

\section{B.4 Proof of Proposition 3}

The unemployment rate for workers with $x<x_{0}$ is a weighted average of $\frac{s}{s+\eta \theta^{1-\alpha}}$, for workers with $x^{*}<x<x_{0}$, and 0 , for workers with $x<x^{*}$. Therefore

$$
\mathbb{E}\left(u \mid x<x_{0}\right)=\frac{\frac{s}{s+\eta \theta^{1-\alpha}}\left(G\left(x_{0}\right)-G\left(x^{*}\right)\right)+0 \cdot G\left(x^{*}\right)}{G\left(x_{0}\right)}=\frac{\frac{s}{s+\eta \theta^{1-\alpha}}\left(G\left(x_{0}\right)-G\left(x^{*}\right)\right)}{G\left(x_{0}\right)} .
$$

The ratio of this unemployment rate to the unemployment rate for workers with ability higher than $x_{0}$ is

$$
\frac{\mathbb{E}\left(u \mid x<x_{0}\right)}{\mathbb{E}\left(u \mid x>x_{0}\right)}=\frac{\frac{s}{s+\eta \theta^{1-\alpha}}\left(G\left(x_{0}\right)-G\left(x^{*}\right)\right)}{G\left(x_{0}\right)} / \frac{s}{s+\eta \theta^{1-\alpha}}=1-\frac{G\left(x^{*}\right)}{G\left(x_{0}\right)} .
$$

This ratio increases with $A_{M}$ since $x^{*}$ decreases with $A_{M}$, as proved in Proposition 1.

\section{B.5 Proof of Lemma 1}

We can solve for market tightness $\theta_{h}$ and $\theta_{l}$ and cutoff ability levels $x_{h}^{*}$ and $x_{l}^{*}$ using the equivalents of equations (9) and (B.9) for the high- and low-educated labor markets in the 
quantitative model:

$$
\begin{gathered}
c=\frac{(1-\beta) \delta \eta \theta_{h}^{-\alpha}}{\beta \delta \eta \theta_{h}^{1-\alpha}+1-\delta+\delta s_{h}}(1-b) \mathbb{E}_{h}\left(x \mid x>x_{h}^{*}\right) \\
\theta_{h}^{1-\alpha}=\frac{\left(A_{T}-A_{M} b x_{h}^{*}\right)\left(1-\delta+\delta s_{h}\right)}{\beta \delta \eta\left(A_{M} x_{h}^{*}-A_{T}\right)} \\
c=\frac{(1-\beta) \delta \eta \theta_{l}^{-\alpha}}{\beta \delta \eta \theta_{l}^{1-\alpha}+1-\delta+\delta s_{l}}(1-b) \mathbb{E}_{l}\left(x \mid x>x_{l}^{*}\right) \\
\theta_{l}^{1-\alpha}=\frac{\left(A_{T}-A_{M} b x_{l}^{*}\right)\left(1-\delta+\delta s_{l}\right)}{\beta \delta \eta\left(A_{M} x_{l}^{*}-A_{T}\right)}
\end{gathered}
$$

where $\mathbb{E}_{h}$ and $\mathbb{E}_{l}$ are computed using $g_{h}(x)$ and $g_{l}(x)$, respectively.

It follows that equation (B.10) that determines $x^{*}$ can, with appropriate subscripting, determine $x_{h}^{*}$ or $x_{l}^{*}$. We showed in the proof of Proposition 1 that the left- (right-) hand side of equation (B.10) is decreasing (increasing) in $x^{*}$. Inspection of the left-hand side of equation (B.10) shows that it is increasing in $s$, hence, any increase in $s$ from $s_{h}$ to $s_{l}$ must increase $x_{l}^{*}$ relative to $x_{h}^{*}$. Inspection of the right-hand side of equation (B.10) shows that it is increasing in $\mathbb{E}\left(x \mid x>x^{*}\right)$; thus, computing the expectation using $g_{h}(x)$ relative to $g_{l}(x)$ must decrease $x_{h}^{*}$ relative to $x_{l}^{*}$, because $G_{h}(x)$ first-order stochastically dominates $G_{l}(x)$. 


\section{Appendix Figures and Tables}

Figure C1: Low-Education Share, $\lambda$, in Model and Data

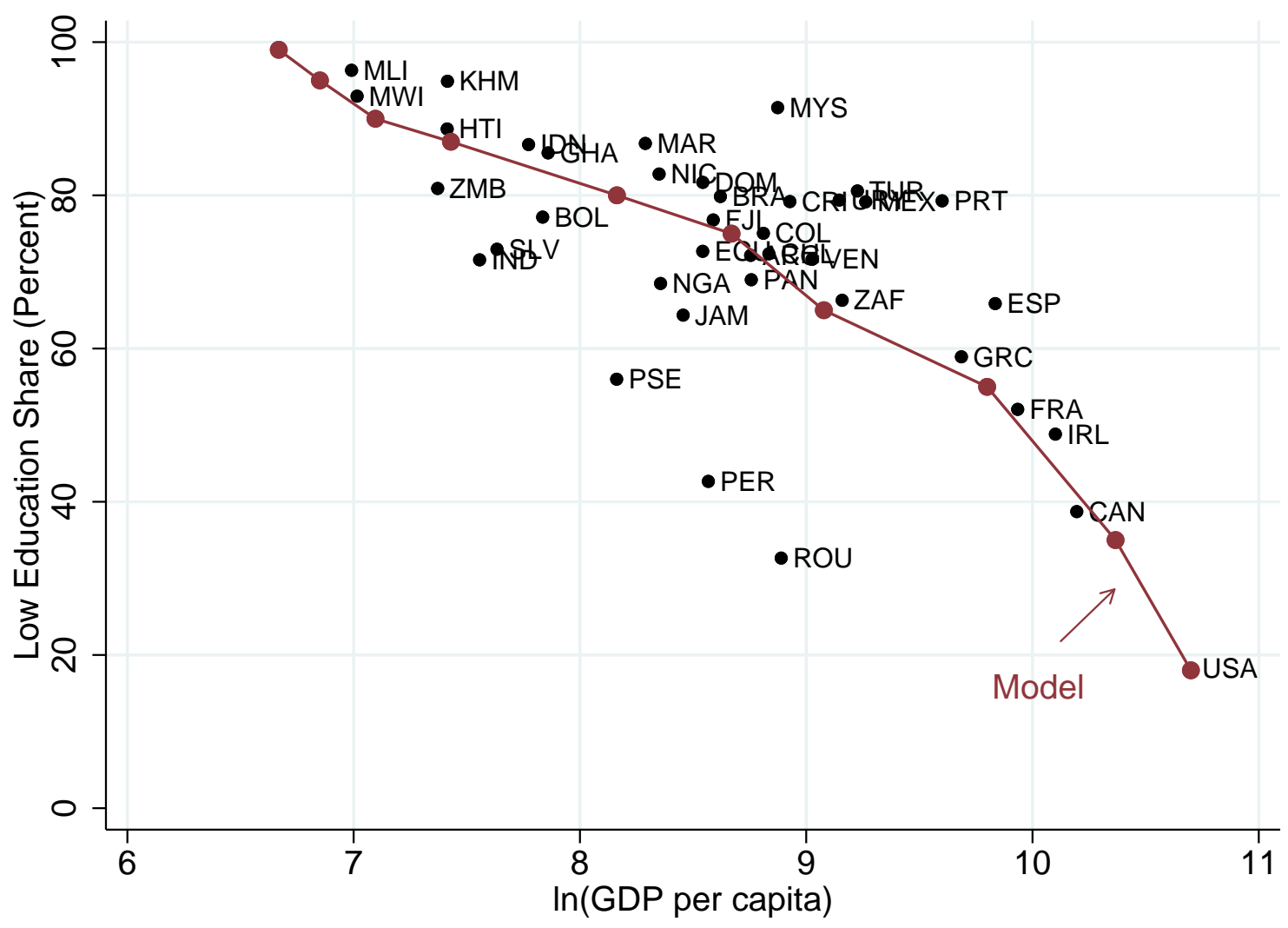

Note: This figure plots the values of $\lambda$ used in the quantitative experiments of Section 5 (solid line), and the percent of the labor force that is low-educated in each of our countries (dots with identifiers). The data come from IPUMS. Low-educated individuals are defined to be those with less than a secondary school education. 
Table C1: Definition of Traditional Sector Goods

\begin{tabular}{l|l}
\hline \hline Item & Details \\
\hline Shoe Repair - Women Street Shoes & $\begin{array}{l}\text { Replacement of } 2 \text { heels (glued and nailed); } \\
\text { While-you-wait in shop service; } \\
\text { Heel: Synthetic polyurethane, small heel. }\end{array}$ \\
\hline Shoe Repair - Men Classic Shoes & $\begin{array}{l}\text { Re-soling rubber soles (glued \& nailed or stitched); } \\
\text { Not "urgent" in shop service. }\end{array}$ \\
\hline Shoeshine & $\begin{array}{l}\text { Cleaning leather shoes with a brush and polishing; } \\
\text { Manual work while keeping the shoes on; }\end{array}$ \\
& Exclude service in a shop. \\
\hline Men basic haircut & $\begin{array}{l}\text { k km in the town center on working days at } 3 \text { p.m.; } \\
\text { Includes: Possible fixed starting fee + price per km; } \\
\text { Excludes: Taxi called by telephone. }\end{array}$ \\
\hline Ladies haircut - long hair & $\begin{array}{l}\text { Scissor cut of short hair for male adults; } \\
\text { Type of establishment: Common men's barber shop; } \\
\text { No shampoo/washing nor styling/fixing products; } \\
\text { Full price including tips if any. }\end{array}$ \\
\hline Manicure & $\begin{array}{l}\text { Hair with curlers cut to medium (basic) for female adult; } \\
\text { Shampoo/washing, blow drying, and styling/fixing products; } \\
\text { Establishment: Common hairdresser (exclude hair stylist). }\end{array}$ \\
\hline & $\begin{array}{l}\text { Long hair cut to short for female adult; } \\
\text { Shampoo/washing, blow drying, styling/fixing products; } \\
\text { Establishment: Common hairdresser (exclude hair stylist). }\end{array}$ \\
\hline $\begin{array}{l}\text { Establishment: Professional beautician; } \\
\text { Bath, filing, cuticles treatment, one-color varnishing. }\end{array}$ \\
\hline
\end{tabular}

Note: The table reports the definitions of each ICP traditional service used in Table 6 , and described in Section 5.2. The services come from the unpublished ICP 2011 Global Core list of goods and services. 
Table C2: Slope Coefficients in the Alternative Calibration

\begin{tabular}{lcc|c}
\hline \hline & Data & Model & Alternative Cali. \\
\hline Aggregate traditional sector share & -15.9 & -13.4 & -15.9 \\
Traditional-sector share for low educated & -16.7 & -12.7 & -15.2 \\
Traditional-sector share for high educated & -4.9 & -5.0 & -6.7 \\
Aggregate unemployment rate & 1.8 & 0.5 & 0.7 \\
Unemployment rate for low-educated & 3.2 & 1.7 & 1.9 \\
Unemployment rate for high-educated & 0.5 & 0.4 & 0.4 \\
Ratio of unemployment rates $u_{l} / u_{h}$ & 0.5 & 0.3 & 0.3 \\
Relative price $P_{T}$ & 0.6 & 0.60 & 0.67 \\
\hline \hline
\end{tabular}

Note: The table reports slope coefficients from regressions of the statistics in each row on log GDP per capita. 